\title{
The spiroquinazoline family of alkaloids: a review
}

\author{
David J. Hart \\ The Ohio State University, Department of Chemistry, $120 \mathrm{~W} .18^{\text {th }}$ Avenue, \\ Columbus, OH 43210, USA \\ E-mail: mailto:hart@chemistry.ohio-state.edu
}

This review is dedicated to Professor James Cook, my former GTA and a long-time contributor to the field of alkaloid chemistry, on the occasion of his $65^{\text {th }}$ birthday

\begin{abstract}
The article presents a review of the structures, biological activities and studies directed toward syntheses of the spiroquinazoline family of alkaloids.
\end{abstract}

Keywords: Alkaloids, total synthesis, oxindoles, hetero-Diels-Alder, $N$-acyliminium ions

\section{Table of Contents}

1. Introduction

2. Structures

2.1 Isolation and structure determination

2.2 Spectroscopy

2.3 Biosynthetic speculation

3. Biological activities

4. Synthesis

4.1 Total synthesis alantrypinone and ent-alantrypinone

4.2 Total synthesis of serantrypinone

4.3 Total synthesis of lapatin B

4.4 Approaches to spiroquinazoline

5. Conclusions

6. Acknowledgements

7. References 


\section{Introduction}

In 1994 Barrow and Sun, from the Sterling-Winthrop group, reported the structure of spiroquinazoline 1, a fungal metabolite isolated during a search for compounds that would inhibit the binding of the neuropeptide substance-P (SP) to the human NK-1 receptor. ${ }^{1}$ Spiroquinazoline was truly a unique natural product at the time. No other natural products containing the carbon skeleton present in spiroquinazoline had been reported. In the 15 years that have followed the Barrow-Sun report, several more natural products that closely resemble spiroquinazoline have been reported as isolates from a variety of fungi. This review will describe the isolation and structures of these natural products, their biological properties, and several approaches to the synthesis of selected members of what will now be called the spiroquinazoline family of natural products (Figures 1-4). Several numbering schemes appear in the literature in regard to the spiroquinazoline family of natural products. The numbering scheme originally used to describe spiroquinazoline will be used throughout this review.

\section{Structures}

\subsection{Isolation and structure determination}

Spiroquinazoline 1 was isolated from ethyl acetate extracts of a fermentation broth derived from Aspergillus flavipes, followed by additional solvent partitioning and chromatography. A total of $16 \mathrm{mg}$ of 1 was isolated from 2.75 liters of fermentation broth. The structure of 1 was assigned largely on the basis of NMR spectroscopy although other analytical tools were used to provide evidence for substructures within the natural product. For example, the molecular formula was established by high resolution FAB-MS, and the UV spectrum indicated the presence of a quinazolinone, a heterocyclic substructure that appears in a wide variety of natural products. ${ }^{2}$ The four-spin systems of the two aromatic rings (C-5-C-8 and C-18-C-21) were identifiable in the ${ }^{1} \mathrm{H}$ NMR spectrum, as well as two exchangeable protons $(\mathrm{NH})$, an isolated methyl group $\left(\mathrm{C}_{2}\right.$ $\mathrm{Me}$ ), a methylene group ( $\mathrm{C}-12)$ coupled to a methine (C-11), and a methine (C-14) with longrange coupling to a methylene $(\mathrm{C}-15)$. The connectivity of the aforementioned spin systems was established using a variety of NMR experiments (COSY and HMQC). The stereochemistry at C14 was established by nOe experiments that established the proximity of this proton to the C-2 methyl group (rather than the C-12 methylene). The absolute configuration of spiroquinazoline was not determined. 


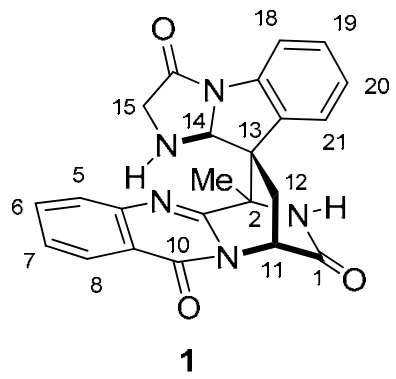

Figure 1. Structure of spiroquinazoline 1.

Over ten years passed before the structure of lapatin A 2 was reported by Larsen and coworkers. ${ }^{3}$ This natural product was isolated from extracts of Penicillium lapatayae (5.3 $\mathrm{mg}$ of 2 isolated from 200 Petri dishes inoculated with the fungus and grown for 14 days) in a search guided by an automated comparison of UV spectra with those of known compounds. The UV spectrum of 2 was a good match with that of spiroquinazoline and LC-MS established the molecular formula of the natural product. NMR spectroscopy again was the major tool used to establish the structure of lapatin A 2, including the relative stereochemistry. An nOe between the lactam $\mathrm{NH}$ and $\mathrm{C}-21$ aromatic-ring proton established stereochemistry at the spiro center (C-13), an nOe between the $\mathrm{H}-14$ and $\mathrm{H}-12$ indicated stereochemistry at the $N, N$-acetal $(\mathrm{C}-14)$, and an nOe between the methyl group at C-15 and H-2 established stereochemistry at C-15 Thus, the major structural differences between 2 and $\mathbf{1}$ were (1) the substitution pattern at C-2 (methyl in $\mathbf{1}$ and hydrogen in 2), (2) the amino acid involved in bridging C-14 to the indoline nitrogen (glycine in $\mathbf{1}$ and alanine in 2), and (3) a difference in stereochemistry at C-14 relative to the C12 methylene group. The absolute stereochemistry of lapatin A was also assigned as shown in Figure 2. The basis of this assignment will be explained later in this section.

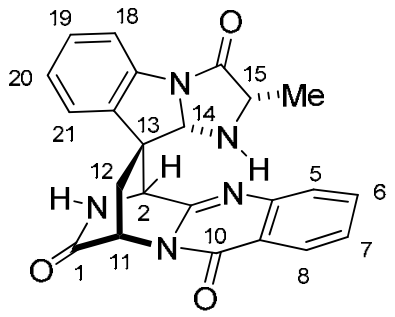

2

Figure 2. Structure of lapatin A 2.

The structures of three more alkaloids closely related to spiroquinazoline were reported by the Rodrigues-Filho group in 2005 (Figure 3). ${ }^{4}$ These compounds were produced by a Eupenicillium fungus isolated from leaves of the plant Murraya paniculata. Alanditrypinone 3 (121 mg), alantryphenone $4(6 \mathrm{mg})$ and alantryleunone $5(2.8 \mathrm{mg})$ were isolated from extracts of 
cultures of Eupenicillium mycelia grown on white corn for three weeks. The structures of 3-5 were based largely on NMR spectroscopy. As with spiroquinazoline, the relative stereochemistry at $\mathrm{C}-14$ in 3 was established by nOe experiments that showed the proximity of $\mathrm{H}-14$ to the C-2 methyl group (rather than $\mathrm{C}$-12 methylene). The trans-relationship between the hydrogens at $\mathrm{C}$ 14 and C-15 was also established by nOe experiments. Thus the relative stereochemistry of alanditrypinone was assigned as shown in Figure 3. The structure of alantryphenone 4 was assigned on the basis of similar spectroscopic data, and the structure of alantryleunone 5 was assigned by analogy. The absolute stereochemistry of alkaloids 3-5 was not determined. It is notable and puzzling that the relative stereochemistry between C-14 and C-15 of lapatin A 2 is different from that reported for alkaloids 3-5 (hydrogens cis in $\mathbf{2}$ and trans in 3-5).

In 2009 the Tomoda group reported the structure of fungal metabolite quinadoline B 6 (6.5 mg isolated from $20 \mathrm{~L}$ of fermentation broth of Aspergillus sp. FKI-1746). ${ }^{5}$ The structure of 6 was ultimately determined by X-ray crystallography. The C-15 stereogenic center was shown to have the $S$-configuration by degradation studies that afforded L-proline, thus defining the absolute configuration of quinadoline B as shown in Figure 3.

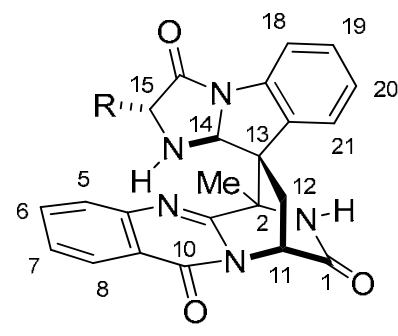

$3 \mathrm{R}=3$-indolylmethyl

$4 \mathrm{R}=$ benzyl

$5 \mathrm{R}=$ isobutyl

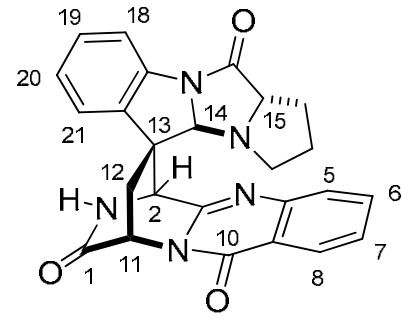

6

Figure 3. Structures of alanditrypinone 3, alantryphenone 4, alantryleunone 5 and quinadoline B 6.

Alkaloids 1-6 have the same carbon skeleton, if one excludes the C-2 and C-15 substituents. In 1998 the Larsen group reported the structure alantrypinone 7 isolated from cultures of the fungus Penicillium thymicola (18 mg isolated from $2 \mathrm{~L}$ of broth). Alantrypinone differs from spiroquinazoline by virtue of the higher oxidation state at $\mathrm{C}-14$, and necessarily, the absence of an amino acid bridge between $\mathrm{C}-14$ and the oxindole nitrogen. 

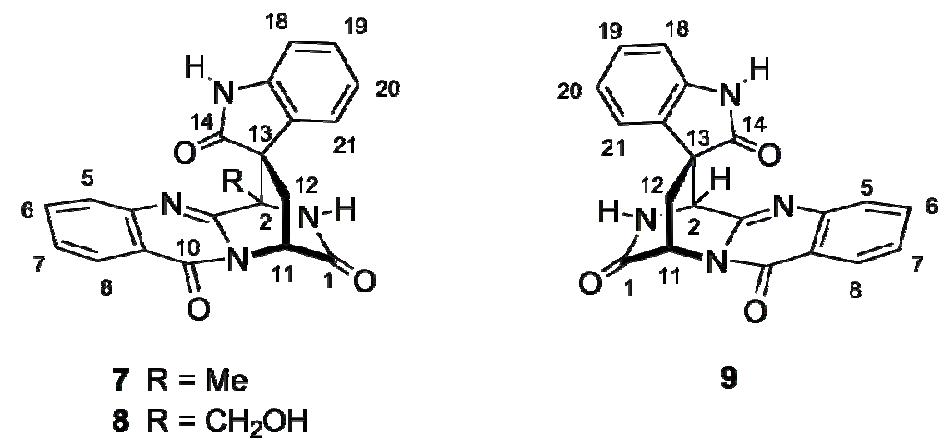

9

Figure 4. Structures of alantrypinone 7, serantrypinone 8 and lapatin B 9.

The structure of alantrypinone was established by X-ray crystallography (Figure 4). ${ }^{6}$ Alantrypinone co-crystallized with DMSO and acetonitrile and thus, it was possible to determine its absolute configuration using the anomalous dispersion technique. Finally, the CD spectrum of 7 was essentially the mirror image (opposite Cotton effect) of the CD spectrum of lapatin A 2 (vide supra). These data provided the rationale for assigning the absolute configuration of lapatin A as shown in Figure 2. Alantrypinone has since been isolated from extracts of Aspergillus terreus (111 mg from $8 \mathrm{~kg}$ of culture) and several other fungal strains of the genus Penicillium. ${ }^{7,8}$

Two structurally related oxindole alkaloids have been reported. Serantrypinone 8 was reported by the Larsen group ( $6 \mathrm{mg}$ from Penicillium thymicola) in $2001 .{ }^{9}$ Screening of a number of fungal cultures in an assay directed at identifying insect GABA receptor inhibitors also lead to the isolation of 8 from Aspergillus terreus (56 mg from $8 \mathrm{~kg}$ of culture broth). The structure of 8 was assigned on the basis of NMR spectroscopy. The CD spectrum of serantrypinone from Penicillium thymicola was essentially identical to that of alantrypinone, leading to assignment of absolute configuration as shown in Figure 4. The sign of the specific rotation of serantrypinone isolated from Aspergillus terreus (levorotatory), ${ }^{7}$ however, was opposite to that isolated from Penicillium thymicola (dextrorotatory). ${ }^{9}$ It was subsequently shown, by comparison of synthetic material with natural product, that both fungi produce the same enantiomer of serantrypinone (vide infra).

Lapatin B 9 (2.5 mg) has been isolated as a congener with lapatin A (vide supra), from Penicillium lapatayae $(2.5 \mathrm{mg}){ }^{3}$ The structure was assigned on the basis of spectroscopic data (mainly NMR). The absolute configuration was based on its CD spectrum (same Cotton effect as lapatin A and opposite Cotton effect as alantrypinone and serantrypinone) and has been confirmed by synthesis (vide infra).

Finally, the indoline-containing structure $\mathbf{1 0}$ was reported for alantrypinene B, a minor compound also isolated by the Rodrigues-Filho group from Eupenicillium fungus (Figure 5). ${ }^{4}$ This structure, however, has recently been retracted based on a comparison of signals for the natural product with those of spiroindoline 11 (critical signals noted at C-14, C-17, and C-22 in Figure 5). ${ }^{10 \mathrm{a}-\mathrm{c}}$ 

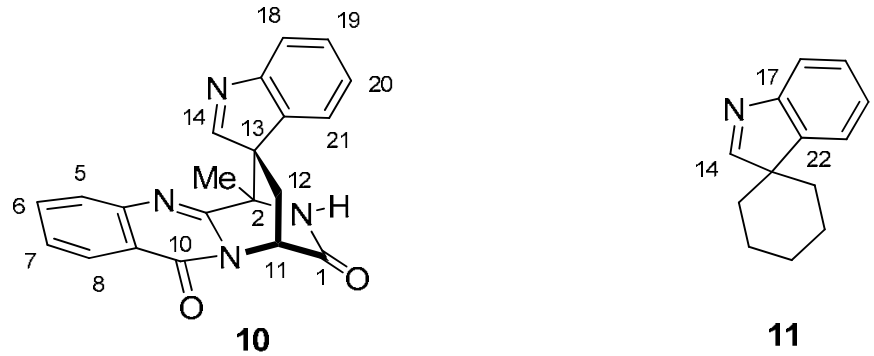

Figure 5. Structure proposed for alantrypinene B 10 and model 11 for NMR analyses.

In summary, nine members of the spiroquinazoline family of natural products have been reported. The complete structures of five of these alkaloids have been established $\mathbf{2}$ and 6-9. The structures of four of the remaining alkaloids $\mathbf{1}$ and 3-5 seem secure based on spectroscopic data, but their absolute stereochemistry is uncertain. It appears that application of circular dichroism (CD) spectroscopy to these materials should resolve this issue.

\subsection{Spectroscopy}

Selected chemical shifts taken from ${ }^{1} \mathrm{H}$ and ${ }^{13} \mathrm{C}$ NMR spectra of $\mathbf{1 - 9}$ are shown in Tables 1 and 2. Trends can be seen that may be of value to research groups identifying new members of this family of natural products, or determining the structures of compounds prepared as intermediates in synthetic studies. For example, H-8 and H-6 in the quinazolinone ring always appear downfield ( $\delta 8.18-8.32$ and $\delta 7.67-7.90$, respectively) relative to other aryl hydrogens, due to the electron-withdrawing nature of the C-9 carbonyl group. Presumably due to the different orientation of the indoline $\mathrm{N}$-acyl groups, $\mathrm{H}-18$ is upfield in the oxindoles $\mathbf{7 - 9}$ relative to $\mathrm{H}-18$ in the indolines 1-6.

It has already been mentioned that all of the natural products described in section 2.2 display UV spectra typical of quinazolinones. The spectra consist of a series of absorption maxima with diminishing extinction coefficients in a range from approximately 210 to $315 \mathrm{~nm}$. For a side-byside comparison of the of lapatin A 2, alantrypinone 7 and lapatin B 9 the reader is referred to the primary literature. ${ }^{3}$

As mentioned above, CD spectra for lapatin A 2, alantrypinone 7, serantrypinone 8 and lapatin B 9 have been reported. Lapatins A and B show similar Cotton effects, while 7 and 8 have similar but opposite Cotton effects (relative to 2 and 9), resulting (in part) in the absolute configuration assignments depicted in Figures 2 and 3. 
Table 1. Chemical shifts $(\delta)$ for selected protons in compounds 1-9

\begin{tabular}{cccccccccc}
\hline $\mathrm{Cpd}^{\mathrm{a}}$ & $\mathbf{1}$ & $\mathbf{2}$ & $\mathbf{3}$ & $\mathbf{4}$ & $\mathbf{5}$ & $\mathbf{6}$ & $\mathbf{7}$ & $\mathbf{8}$ & $\mathbf{9}$ \\
\hline $\mathrm{H}-5$ & 7.70 & 7.64 & 7.70 & 7.82 & 7.73 & 7.70 & 7.68 & 7.75 & 7.67 \\
$\mathrm{H}-6$ & 7.76 & 7.84 & 7.85 & 7.90 & 7.80 & 7.79 & 7.85 & 7.89 & 7.87 \\
$\mathrm{H}-7$ & 7.52 & 7.56 & 7.59 & 7.60 & 7.53 & 7.50 & 7.58 & 7.61 & 7.60 \\
$\mathrm{H}-8$ & 8.30 & 8.18 & 8.28 & 8.27 & 8.34 & 8.29 & 8.19 & 8.22 & 8.22 \\
$\mathrm{H}-11$ & 5.67 & 5.48 & 5.66 & 5.69 & 5.57 & 5.87 & 5.58 & 5.55 & 5.55 \\
$\mathrm{H}-12$ & 1.88 & 2.44 & 1.85 & 1.80 & 1.83 & 2.35 & 2.41 & 2.36 & 2.38 \\
$\mathrm{H}-12$ & 3.26 & 2.62 & 3.19 & 3.28 & 3.10 & 2.65 & 2.53 & 2.41 & 2.41 \\
$\mathrm{H}-14$ & 5.47 & 5.32 & 5.04 & 4.99 & 5.42 & 5.37 & - & - & - \\
$\mathrm{H}-15$ & 7.67 & 7.87 & 7.60 & 8.22 & 6.94 & 7.31 & - & - & - \\
$\mathrm{H}-18$ & 7.55 & 7.46 & 7.53 & 7.60 & 7.50 & 7.54 & 6.95 & 6.89 & 6.94 \\
$\mathrm{H}-19$ & 7.33 & 7.40 & 7.32 & 7.36 & 7.23 & 7.32 & 7.31 & 7.29 & 7.31 \\
$\mathrm{H}-20$ & 7.16 & 7.23 & 7.14 & 7.18 & 7.20 & 7.11 & 7.11 & 7.07 & 7.09 \\
$\mathrm{H}-21$ & 7.51 & 7.16 & 7.43 & 7.43 & 7.32 & 7.33 & 7.18 & 7.22 & 7.20 \\
$2-\mathrm{X}^{\mathrm{b}}$ & 1.74 & 4.62 & 1.55 & 1.57 & 1.77 & 4.62 & 1.19 & - & 4.33 \\
\hline
\end{tabular}

${ }^{a}$ Spectra taken in $\mathrm{CDCl}_{3}$ except for 7 (DMSO- $\left.d_{6} / \mathrm{CD}_{3} \mathrm{CN}, 10: 1\right)$ and 8, 9, (DMSO- $\left.d_{6}\right)$.

${ }^{\mathrm{b}} \mathrm{Chemical}$ shift of $\mathrm{Me}$ or $\mathrm{H}$ on $\mathrm{C}-2$; shift of $\mathrm{CH}_{2} \mathrm{OH}$ for 8 at $\delta 3.57$ and 3.71 .

Table 2. Chemical shifts $(\delta)$ for selected carbons in compounds 1-9

\begin{tabular}{cccccccccc}
\hline $\mathrm{Cpd}^{\mathrm{a}}$ & $\mathbf{1}$ & $\mathbf{2}$ & $\mathbf{3}$ & $\mathbf{4}$ & $\mathbf{5}$ & $\mathbf{6}$ & $\mathbf{7}$ & $\mathbf{8}$ & $\mathbf{9}$ \\
\hline $\mathrm{C} 1$ & 171.3 & 170.2 & 174.8 & 170.2 & 172.3 & 170.7 & 169.5 & 169.6 & 169.3 \\
$\mathrm{C} 2$ & 61.8 & 56.6 & 65.0 & 63.3 & 63.1 & 60.6 & 61.9 & 64.9 & 58.8 \\
$\mathrm{C} 3$ & 152.6 & 152.7 & 155.2 & 155.2 & 154.3 & 151.1 & 152.7 & 152.0 & 151.0 \\
$\mathrm{C} 4$ & 146.7 & 147.5 & 149.8 & 147.1 & 150.1 & 146.6 & 146.9 & 146.5 & 146.9 \\
$\mathrm{C} 5$ & 127.9 & 127.2 & 127.6 & 127.1 & 127.5 & 127.1 & 127.2 & 127.6 & 127.1 \\
$\mathrm{C} 6$ & 136.7 & 134.5 & 134.6 & 134.0 & 134.0 & 135.0 & 134.0 & 134.5 & 134.5 \\
$\mathrm{C}-7$ & 127.7 & 126.7 & 127.5 & 127.0 & 127.0 & 127.8 & 126.5 & 127.1 & 125.9 \\
$\mathrm{C}-8$ & 127.2 & 126.3 & 127.0 & 126.2 & 126.2 & 127.3 & 126.0 & 126.1 & 126.2 \\
$\mathrm{C}-9$ & 120.6 & 120.2 & 123.7 & 120.3 & 123.7 & 120.9 & 120.2 & 120.1 & 120.1 \\
$\mathrm{C}-10$ & 158.9 & 158.5 & 161.0 & 162.4 & 161.3 & 158.7 & 158.4 & 158.3 & 158.1 \\
$\mathrm{C}-11$ & 52.0 & 53.1 & 52.1 & 53.0 & 52.3 & 53.0 & 51.8 & 51.9 & 52.4 \\
$\mathrm{C}-12$ & 33.3 & 36.2 & 33.0 & 33.0 & 25.0 & 33.9 & 35.9 & 37.3 & 34.5 \\
$\mathrm{C}-13$ & 56.4 & 51.4 & 55.0 & 55.8 & 55.8 & 53.5 & 54.7 & 52.5 & 51.0 \\
$\mathrm{C}-14$ & 81.1 & 83.4 & 80.0 & 77.5 & 79.8 & 91.8 & 176.6 & 176.8 & 176.4 \\
$\mathrm{C}-15$ & 52.8 & 58.8 & 63.0 & 64.3 & 62.0 & 69.4 & - & - & - \\
$\mathrm{C}-16$ & 170.1 & 171.0 & 174.5 & 173.2 & 170.0 & 174.1 & - & - & - \\
$\mathrm{C}-17$ & 138.0 & 136.8 & 141.0 & 139.0 & 139.5 & 137.7 & 142.4 & 142.4 & 141.7 \\
$\mathrm{C}-18$ & 116.2 & 114.3 & 116.3 & 115.0 & 116.5 & 116.8 & 109.5 & 109.6 & 109.7 \\
\hline
\end{tabular}


Table 2. Continued

\begin{tabular}{cccccccccc}
\hline $\mathrm{Cpd}^{\text {a }}$ & $\mathbf{1}$ & $\mathbf{2}$ & $\mathbf{3}$ & $\mathbf{4}$ & $\mathbf{5}$ & $\mathbf{6}$ & $\mathbf{7}$ & $\mathbf{8}$ & $\mathbf{9}$ \\
\hline $\mathrm{C}-19$ & 129.4 & 129.1 & 128.0 & 128.4 & 128.0 & 129.6 & 128.8 & 128.9 & 128.9 \\
$\mathrm{C}-20$ & 126.4 & 124.7 & 121.0 & 126.0 & 125.5 & 126.7 & 122.0 & 121.8 & 121.8 \\
$\mathrm{C}-21$ & 124.0 & 125.9 & 124.2 & 123.2 & 128.3 & 123.9 & 123.6 & 123.6 & 123.8 \\
$\mathrm{C}-22$ & 135.5 & 138.0 & 139.1 & 135.0 & 136.3 & 136.8 & 129.8 & 129.6 & 130.5 \\
$2-\mathrm{X}^{\mathrm{b}}$ & 15.0 & - & 15.0 & 14.3 & 17.7 & - & 12.8 & 57.6 & - \\
\hline
\end{tabular}

${ }^{\mathrm{a}}$ Spectra taken in $\mathrm{CDCl}_{3}$ except for 7 (DMSO- $\left.d_{6}-\mathrm{CD}_{3} \mathrm{CN}, 10: 1\right)$ and 8, $9\left(\mathrm{DMSO}-d_{6}\right)$.

${ }^{\mathrm{b}} \mathrm{Chemical}$ shift of $\mathrm{Me}$ or $\mathrm{CH}_{2} \mathrm{OH}$ on $\mathrm{C}-2$.

While alkaloids 1-9 all exhibit appropriate parent ions in their mass spectra, a distinct retroDiels-Alder fragmentation gives the base peak in the MS of six of these compounds (3-5 and 79), regardless of the ionization method used to produce spectra (EI, ES and APCIMS). This fragmentation is illustrated for alantrypinone in Figure 6 in positive ion mode $(\mathbf{7} \rightarrow \mathbf{1 2}+\mathbf{1 3})$. Mass spectroscopy in negative ion mode provides the corresponding peak at $\mathrm{m} / \mathrm{z} 226 .{ }^{4}$ It is likely that this fragment appears in all of the alkaloids shown in Figures 1-4. It is notable that a DielsAlder reaction that accomplishes the reverse of this fragmentation, provides an effective route to oxindole-containing members of the spiroquinazoline family of alkaloids (vide infra). ${ }^{11}$
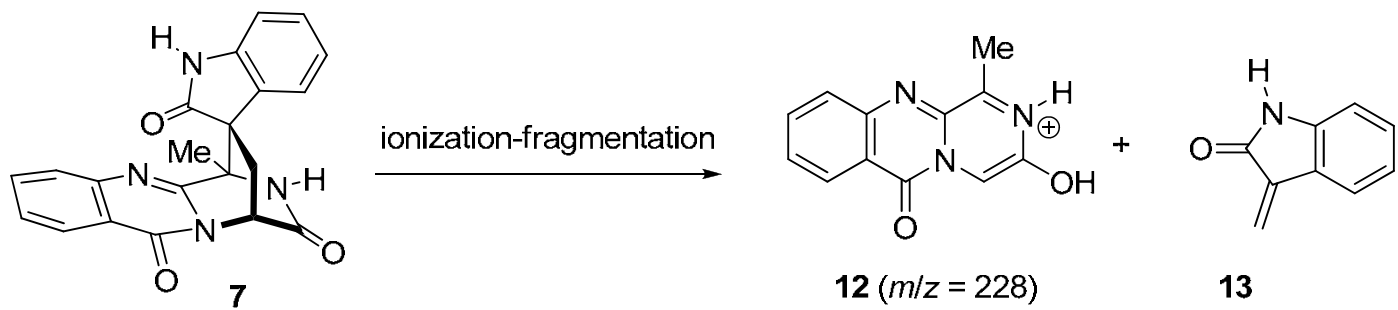

Figure 6. Retro-Diels-Alder fragmentation is typical of spiroquinazoline alkaloids.

\subsection{Biosynthetic speculation}

The structures of the spiroquinazoline family of alkaloids suggest they are derived from amino acids. Anthranilic acid and tryptophan substructures are clearly present in all members of this family of alkaloids as illustrated for spiroquinazoline in Figure 7. The amino acid alanine, or a derivative thereof, is most likely used to incorporate C-3, C-2 and the 2-methyl group for compounds 1, 3-5, and 7. Of course, some oxidation would have to take place at $\mathrm{C}-2$ of the alanine to enable formation of a bond to $\mathrm{C}-13$ ( $\mathrm{C}-3$ of the tryptophan residue). Thus, pyruvate or dehydroalanine might also be involved in the biosynthesis of these alkaloids. Glycine (for 2, 6, and 9) and serine or a dehydroalanine (for 8) would be anticipated to replace alanine for the remaining spiroquinazolines. Finally, an amino acid bridge links the tryptophan-derived substructure from C-14 to the indole-derived nitrogen. This amino acid is glycine in the case of 
spiroquinazoline $\mathbf{1}$ and alanine, tryptophan, phenylalanine, isoleucine and proline, respectively, in the cases alkaloids of 2-6.

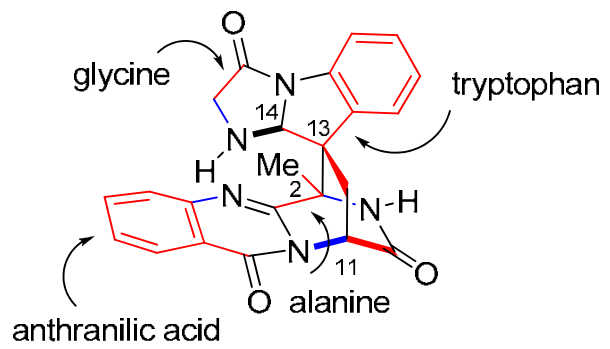

1

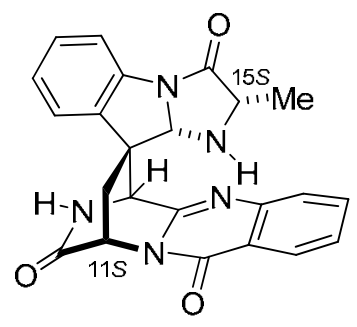

2

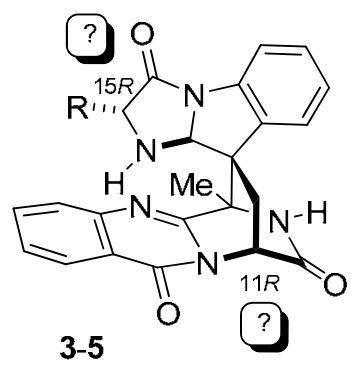

3-5

Figure 7. Proposed biosynthetic origins of spiroquinazoline $\mathbf{1}$ [carbon skeleton in red and a-amino bonds in blue] and lapatin A 2, and stereochemical questions associated with alkaloids 3-5.

The stereochemistry of the tryptophan and bridging amino acids determines the absolute configuration of the alkaloids. The S-configuration at C-11 in lapatin A 2, quinadoline B 6, and lapatin B 9 suggests that L-tryptophan is incorporated into these alkaloids. The $S$-configuration at $\mathrm{C}-15$ indicates that an L-amino acid provides the amino acid bridge in $\mathbf{2}$ and $\mathbf{6}$. The story is different for alantrypinone 7 and serantrypinone 8 . The $R$-configuration at $\mathrm{C}-11$ indicates that $\mathrm{D}-$ tryptophan is incorporated into these alkaloids. Another possibility is that L-tryptophan is incorporated early in the biosynthesis of $\mathbf{7}$ and $\mathbf{8}$, followed by a post-translational epimerization at the incipient $\mathrm{C}-11$ prior to construction of the $\mathrm{C}-2-\mathrm{C}-13$ bond. ${ }^{12}$

The absolute configuration of spiroquinazoline $\mathbf{1}$ and alkaloids $\mathbf{3}-\mathbf{5}$ has yet to be determined. In the case of spiroquinazoline, the only issue is which enantiomer of tryptophan is formally incorporated in the natural product. In the case of alkaloids 3-5, the issue is more complicated. Based on nOe studies, the relative stereochemistry between $\mathrm{C}-11$ and $\mathrm{C}-15$ has been assigned as shown in Figure 3. Thus, if $\mathrm{C}-11$ turns out to have the $R$-configuration (derived from $\mathrm{D}$ tryptophan as for alkaloids 7 and 8), the bridging amino acid would be derived from the corresponding D-amino acid. Of course, if C-11 has the S-configuration, then the bridging amino acid would formally belong to the L-series of amino acids. Barring post-translational epimerization, either two D-series or two L-series amino acids must be incorporated into alkaloids 3-5. CD studies should resolve uncertainties in assignment of absolute configuration of 1 and 3-5. Feeding studies might resolve the question of which enantiomers of tryptophan and the bridging amino acids are really involved in the biosynthesis of these alkaloids.

Before leaving the biosynthetic origins of the spiroquinazolines, it is worth mentioning several biosynthetically related quinazolinone-containing natural products (Figure 8). Glyantrypine $\mathbf{1 4}$ is a fungal metabolite that has been isolated from Aspergillus clavatus. ${ }^{13}$ Feeding studies have shown that anthranilic acid, tryptophan and glycine are incorporated in this natural product. ${ }^{14}$ Whereas both enantiomers of this natural product have been prepared by total 
synthesis, the absolute configuration of this alkaloid is still unknown, in part because DLtryptophan was used in the aforementioned feeding studies.

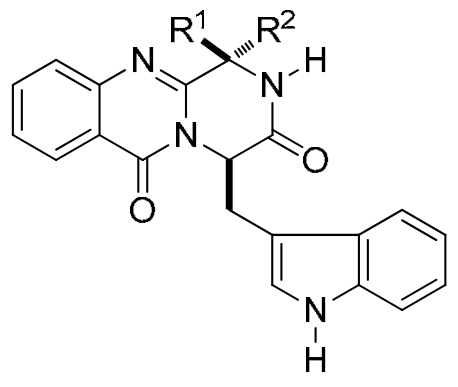

$14 \mathrm{R}^{1}=\mathrm{R}^{2}=\mathrm{H}$ $15 \mathrm{R}^{1}=\mathrm{Me}, \mathrm{R}^{2}=\mathrm{H}$ $16 \mathrm{R}^{1}=\mathrm{H}, \mathrm{R}^{2}=\mathrm{Me}$

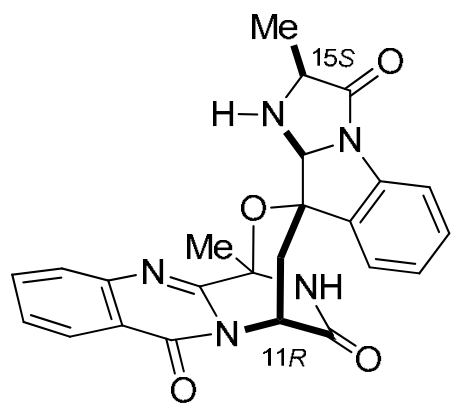

17

Figure 8. Structures of glyantrypine 14 and fumiquinazolines G 15, F 16 and C 17.

Fumiquinazolines G 15 and F 16 have also been isolated from fungi (Penicillium thymicola and Aspergillus fumigatus). In each case the absolute configuration has been determined by synthesis (see Figure 8). ${ }^{15,16}$ It is clear that the fungi produce these natural products with formal introduction of D-tryptophan. Finally, fumiquinazoline C $\mathbf{1 7}$ has been isolated from Aspergillus fumigatus. $^{15}$ The absolute configuration of $\mathbf{1 7}$ was determined by a combination of X-ray crystallography and degradation studies (to give L-alanine) and confirmed by total synthesis. ${ }^{15,17}$ The structure of fumiquinazoline $\mathrm{C}$ clearly resembles the spiroquinazolines, the difference being insertion of an oxygen atom in the bridge connecting C-2 and C-11. Thus, there is ample precedence for the formal incorporation of D-tryptophan into alkaloids closely related to the spiroquinazolines.

\section{Biological Activities}

The reason why fungi produce spiroquinazoline-type alkaloids is not known, but biological activities have been observed for several of these natural products. A brief summary will be presented here.

As mentioned in the introduction, spiroquinazoline was discovered during a search for inhibitors of SP binding to the human NK-1 receptor, possible lead compounds for development of analgesics. Spiroquinazoline 1 inhibited binding of tritiated-SP to human astrocytoma cells (a rich source of NK-1 receptors) with a $K_{i}$ of $95 \mu \mathrm{M} .{ }^{1}$ This is regarded as a low level of activity. ${ }^{18}$

Quinolidine B 6 was initially shown to be a weak inhibitor of lipid droplet synthesis in mouse macrophages. ${ }^{5}$ Lipid droplets have been invoked in the uptake and storage of esters derived from cholesterol (CE) and triacylglyerols (TG) in the development of obesity and atherosclerosis. ${ }^{19}$ 
Further studies showed that $\mathbf{6}$ inhibited CE synthesis with an $\mathrm{IC}_{50}$ of $93 \mu \mathrm{M}$, but had no effect on TG synthesis. ${ }^{5}$ Inhibitors with nearly a thousand-fold greater activity are known and thus, these compounds are unlikely to be of interest for treatment of disorders that involve lipid synthesis.

The isolation of oxindole-containing members of the spiroquinazoline family by the Larsen group was not driven by biology. ${ }^{3,6,8,9}$ However, a search for insect GABA inhibitors from fungal cultures was the driving force behind the discovery of alantrypinone $\mathbf{7}$ and serantrypinone $\mathbf{8}$ by Ozoe and coworkers. ${ }^{7}$ GABA receptors are believed to be targets for several insecticides as they are involved in neurotransmission events associated with the nervous system of insects. Receptor binding was determined by examining extracts for inhibition of tritiated-EBOB 18 (Figure 9) binding to housefly head membranes. It was shown that $\mathbf{7}$ and $\mathbf{8}$ inhibited such binding with $\mathrm{IC}_{50}$ values of $0.34 \mu \mathrm{M}$ and $2.1 \mu \mathrm{M}$, respectively. Since GABA receptors also play important physiological roles in mammals, 7 and $\mathbf{8}$ were also evaluated in rat brain membranes where they exhibited $\mathrm{IC}_{50}$ values of $16 \mu \mathrm{M}$ and $128 \mu \mathrm{M}$, respectively. Thus, 7 and 8 are 47-fold and 61-fold more selective for the insect GABA receptor than the mammalian GABA receptor (in rats). This suggested that these alkaloids might be less toxic toward mammals than insects. ${ }^{7}$

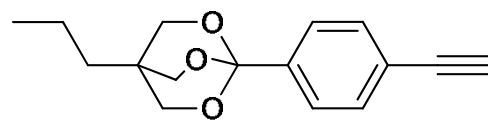

18

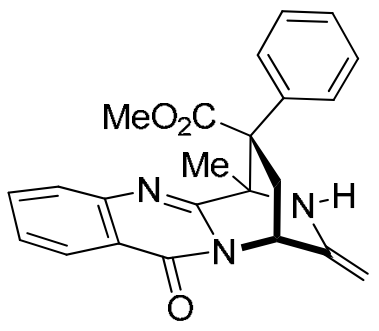

26
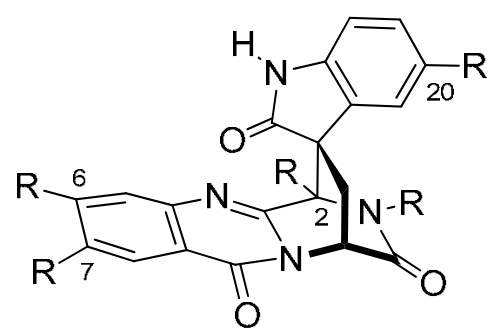

\begin{tabular}{l|llll} 
& 2-R & 6-R & 7-R & 20-R \\
\hline $\mathbf{1 9}$ & $\mathrm{Me}$ & $\mathrm{H}$ & $\mathrm{Cl}$ & $\mathrm{H}$ \\
$\mathbf{2 0}$ & $\mathrm{Me}$ & $\mathrm{H}$ & $\mathrm{F}$ & $\mathrm{H}$ \\
$\mathbf{2 1}$ & $\mathrm{Me}$ & $\mathrm{Cl}$ & $\mathrm{H}$ & $\mathrm{H}$ \\
$\mathbf{2 2}$ & $\mathrm{Me}$ & $\mathrm{H}$ & $\mathrm{H}$ & $\mathrm{Cl}$ \\
$\mathbf{2 3}$ & $\mathrm{Me}$ & $\mathrm{H}$ & $\mathrm{Cl}$ & $\mathrm{Cl}$ \\
$\mathbf{2 4}$ & $\mathrm{Bn}$ & $\mathrm{H}$ & $\mathrm{H}$ & $\mathrm{H}$ \\
$\mathbf{2 5}$ & i-Pr & $\mathrm{H}$ & $\mathrm{H}$ & $\mathrm{H}$
\end{tabular}

Figure 9. Synthetic inhibitors of EBOB 18 binding to housefly head membranes.

Since the initial report from the Ozoe group, it has been shown that ent-alantrypinone and ent-serantrypinone inhibit EBOB binding to housefly head membranes with $\mathrm{IC}_{50}$ values of 2.31 $\mu \mathrm{M}$ and $6.36 \mu \mathrm{M}$, respectively. Thus, the enantiomers of the natural products retain some GABA inhibition activity, and racemic alantrypinone is nearly as active as the natural product. ${ }^{20,21}$ Furthermore it has been shown that lapatin B 9 also inhibits EBOB binding to housefly head membranes with an $\mathrm{IC}_{50}$ of $17 \mu \mathrm{M}$.

Finally, GABA binding inhibition of about 30 racemic synthetic analogs of alantrypinone have been evaluated. ${ }^{21}$ This study identified compounds 19, 20 and 23-25 as inhibitors with $\mathrm{IC}_{50}$ 
values of $1 \mu \mathrm{M}$ or better (similar to alantrypinone itself), and compounds 21, 22 and 26 as compounds with $\mathrm{IC}_{50}$ values of close to $10 \mu \mathrm{M}$. It was also found that alkyl substitution at the lactam nitrogens decreased activity, with substitution at the oxindole nitrogen having the larger effect. C-13 epimers tended to show much reduced activity.

\section{Synthesis}

\subsection{Total Synthesis of Alantrypinone (7) and ent-Alantrypinone (27 or ent-7)}

The first synthesis of ent-alantrypinone 27 was described in 1999. ${ }^{22,23}$ This research was actually a diversion of a synthetic program directed at spiroquinazoline 1, whose synthesis from Ltryptophan was being pursued when the structure of 7 was reported. ${ }^{6}$ The late stages of the synthetic plan were inspired by the biosynthetic speculation described in Section 3 of this review (Scheme 1). It was anticipated that protonation of enamide 29 would be followed by an electrophilic aromatic substitution reaction to provide indole $\mathbf{2 8}$. Transformation of $\mathbf{2 8}$ into oxindole 27 was then to be accomplished using prior art. $^{24}$

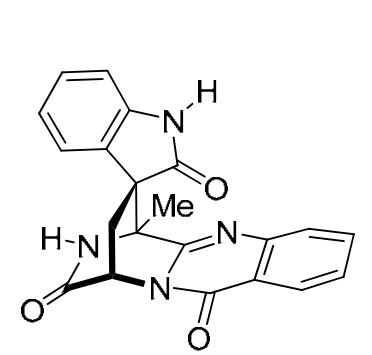

27

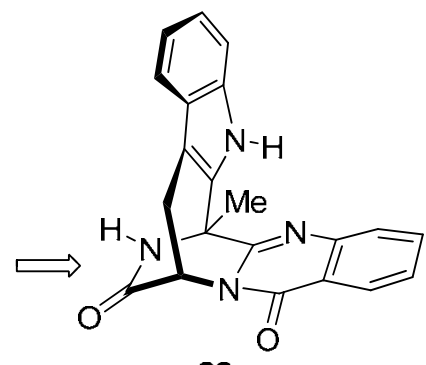

28<smiles>C=CC=C</smiles>

29

Scheme 1. Plan for synthesis of ent-alantrypinone 27.

The synthetic plan was well grounded in the work of Ottenheijm who had shown that diketopiperazine $\mathbf{3 0}$ was converted to $\mathbf{3 2}$ upon treatment with acid, perhaps via indoline $\mathbf{3 1}$ (Scheme 2). ${ }^{25}$ Evidence for the speculation of $\mathbf{3 1}$ as an intermediate was later supplied when $\mathbf{3 3}$ was treated with pyruvoyl chloride (acylation of the hydroxamic acid) followed by trifluoroacetic acid to provide 34 in $72 \%$ yield along with $12 \%$ of indoline 35 as a minor product (Scheme 2 ). ${ }^{26}$ 
<smiles>C=C1NC(=O)C(Cc2cn([13CH3])c3ccccc23)N(O)C1=O</smiles><smiles>C=CCNC(=O)C(Cc1c(C(C)(C)C=C)[nH]c2ccccc12)NO</smiles>

33

\section{1. $\mathrm{CH}_{3} \mathrm{COCOC}$ 2. $\mathrm{CF}_{3} \mathrm{CO}_{2} \mathrm{H}$}

$34(72 \%)$

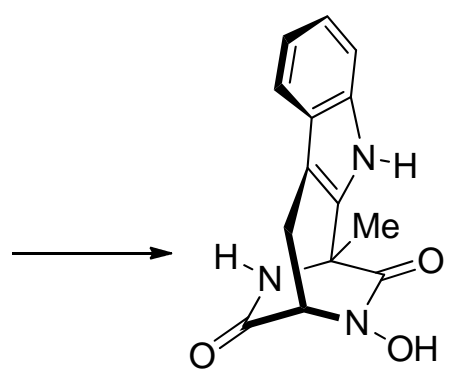

32<smiles>C=CCN1C(=C)C(=O)N(O)C(Cc2c(C(C)(C)C=C)[nH]c3ccccc23)C1=O</smiles><smiles>[R]C(=O)C1N(O)C(=O)C2C([M])C3(C([R])=Nc4ccccc43)C([R])N21</smiles>

$35(12 \%)$

$\mathrm{R}_{1}=1,1$-dimethylallyl $\mathrm{R}_{2}=$ allyl

Scheme 2. Ottenheijm's studies in the field of diketopiperazine chemistry.

The synthesis of ent-alantrypinone 27 began with the preparation of enamide 29 as shown in Scheme 3. This material had previously been prepared by Snider using a different route. ${ }^{16 a}$ Acylation of dipeptide 38, prepared from L-tryptophan methyl ester 36 and isatoic anhydride 37, with the acid chloride derived from $N$-Fmoc-S-methylcysteine gave tripeptide 39. This material was converted to iminobenzoxazine 40, which rearranged to quinazolinone 42 upon treatment with $\mathrm{Li}\left[\mathrm{Me}_{3} \mathrm{AlSPh}\right],{ }^{27}$ possibly via the intermediacy of iminothioester 41. Removal of the Fmoc group provided 43. This cyclodehydration procedure is a modification of the GanesanMazurkiewicz cyclization, a process that has played an important role in the synthesis of a number of quinazolinone-containing alkaloids. ${ }^{16 \mathrm{a}-16 \mathrm{~d}, 28}$

The synthesis of $\mathbf{2 9}$ was completed by oxidation of sulfide $\mathbf{4 3}$ to a mixture of diastereomeric sulfoxides 44 followed by elimination of methanesulfenic acid in the presence of triphenylphosphine as a sulfenic acid trap. 
<smiles>O=c1[nH]c2ccccc2c(=O)o1</smiles><smiles>COC(=O)C(N)Cc1c[nH]c2ccccc12</smiles>

36<smiles>COC(=O)C(Cc1c[nH]c2ccccc12)n1c(C(CS(C)(=O)=O)NC(F)F)nc2ccccc2c1=O</smiles><smiles>CS(=O)(=O)c1ccccc1</smiles><smiles></smiles>

41

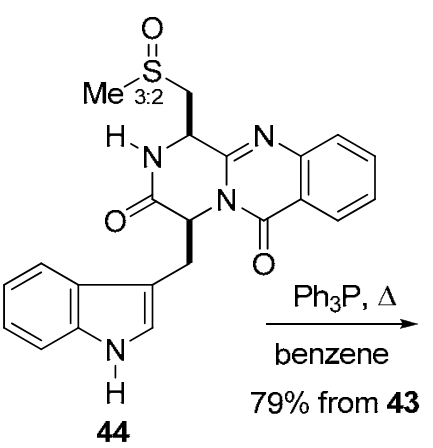

MeS

$\mathrm{MeO}$<smiles>[Li]</smiles><smiles>C[123I]</smiles><smiles>N</smiles>

38

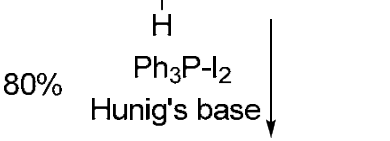<smiles>COCCN=c1oc(CN=C2CCCCC2)nc2ccccc12</smiles><smiles>COC(=O)C(N)Cc1c[nH]c2ccccc12</smiles>

40<smiles>C=C1NC(=O)[C@H](Cc2c[nH]c3ccccc23)n2c1nc1ccccc1c2=O</smiles>

Scheme 3. Preparation of enamide 29 en route to ent-alantrypinone.

The synthesis of ent-alantrypinone 27 was completed in three steps as shown in Scheme 4. Treatment of 29 with trifluoroacetic acid gave bridged indole 28 as expected based on the precedence provided in Scheme 2. Treatment of $\mathbf{2 8}$ with NBS under aqueous acidic conditions provided a mixture brominated oxindoles (largely brominated at C-20). Hydrogenolysis of the aryl bromides gave ent-alantrypinone (27 or ent-7) and the C-13-epimer of ent-alantrypinone 45. As well documented in the literature, the indole-oxindole conversion most likely passes through an intermediate bromohydrin and/or the corresponding indoline. Oxindoles 27 and 45 were readily separated by chromatography over silica gel. This is presumably a result of the oxindole 
lactam in $45\left[\mathrm{R}_{f}\left(\mathrm{SiO}_{2}\right)=0.34\right.$ in EtOAc] being much more accessible to the silica gel surface than the corresponding lactam in $27\left[\mathrm{R}_{f}\left(\mathrm{SiO}_{2}\right)=0.49\right.$ in EtOAc]. The ${ }^{1} \mathrm{H}$ NMR spectra of 27 and 45 were similar with a glaring exception in the chemical shift values for the oxindole aromatic protons. Most notable is the appearance of $\mathrm{H}-21$ at $\delta 5.87$, an upfield shift (relative to alantrypinone) that no doubt reflects its disposition to the $\pi$-system of the quinazolinone ring system. The polarity and spectroscopic differences noted for ent-7 and $\mathbf{4 5}$ appear to be reliable markers for distinguishing these $\mathrm{C}-13$ epimers from one another.
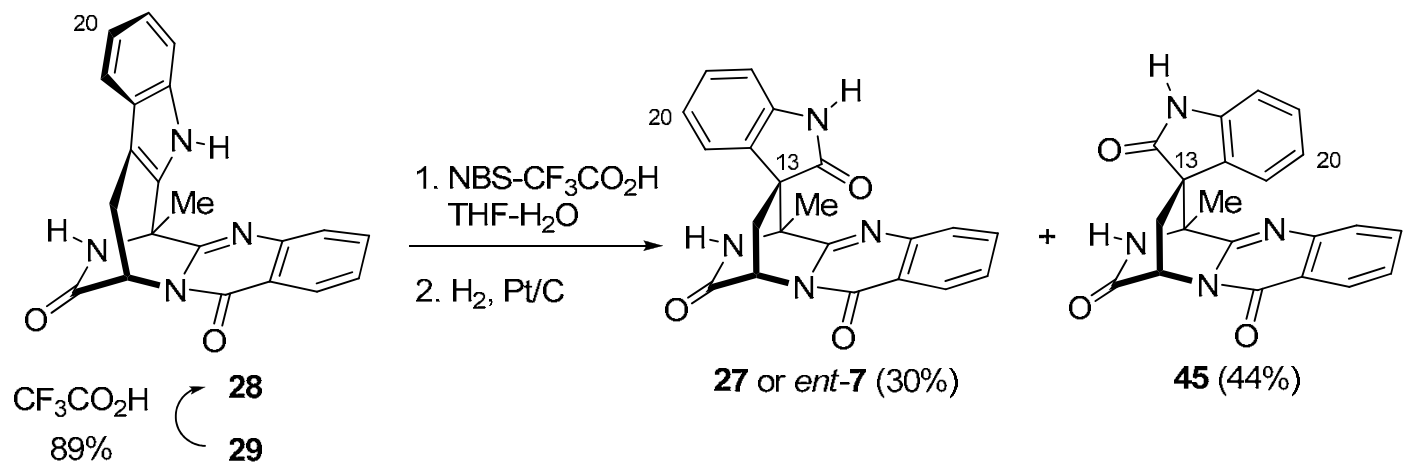

Scheme 4. Synthesis of ent-alantrypinone (27 or ent-7) and its C-13 epimer 45.

The synthesis of ent-alantrypinone 27 confirmed the absolute stereochemical assignment for alantrypinone $\mathbf{7}$ made earlier on the basis of X-ray crystallography. ${ }^{6}$ The conversion of indole 28 to oxindole 27, however, lacked stereocontrol at C-13. A racemic synthesis of alantrypinone, reported by the Kende group, presents an interesting solution to this problem. ${ }^{29,30}$

The Kende synthesis follows the Diels-Alder route eluded to in the discussion of Figure 6 (vide supra). The key reaction is a cycloaddition between heterocyclic dienophile 52 (Scheme 5) and 3-alkylidene oxindoles. Dienophile 52 was prepared in six steps as shown in Scheme 5. Anthranilic acid 46 was converted lactam 50 via a reaction sequence that relied on the aforementioned Ganesan-Mazurkiewicz cyclization. Ethylation of the lactam oxygen gave $5 \mathbf{1}$ and oxidation using DDQ to provided dienophile $\mathbf{5 2}$ as a crystalline solid. 


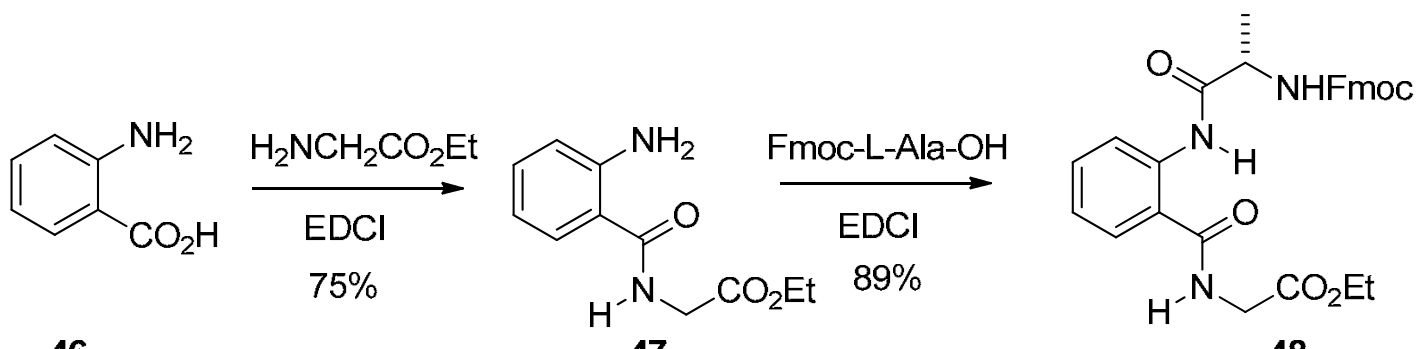

46

47

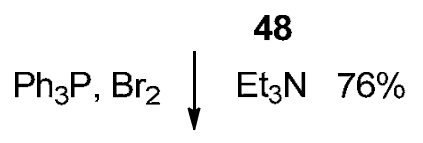<smiles>[B]OC1Cn2c(nc3ccccc3c2=O)[C@@H](C)N=C1OCC</smiles><smiles>C[C@H]1NC(=O)Cn2c1nc1ccccc1c2=O</smiles>

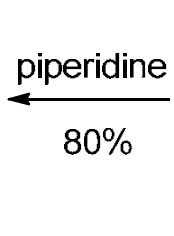<smiles>CCOC(=O)CN=c1oc([C@H](C)NCPC)nc2ccccc12</smiles><smiles>CCOc1cn2c(=O)c3ccccc3nc2c(C)n1</smiles>

52

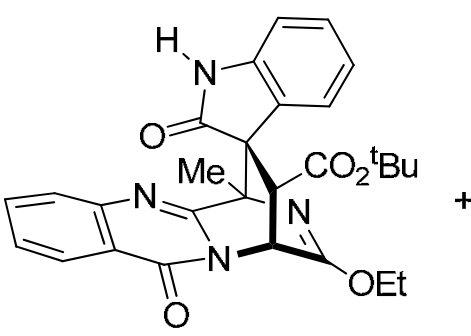

$54(65 \%)$

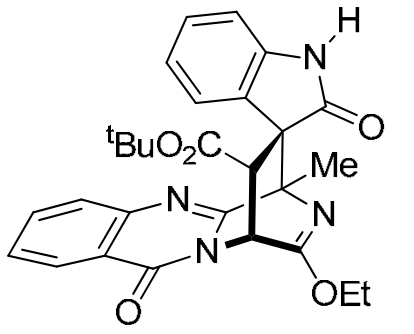

$55(15 \%)$<smiles>CC(C)(C)OC(=O)/C=C1/C(=O)Nc2ccccc21</smiles>

1. $\mathrm{HCl}$, EtOAc $\downarrow$ 2. $\mathrm{CF}_{3} \mathrm{CO}_{2} \mathrm{H}$

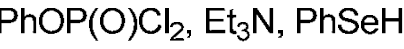

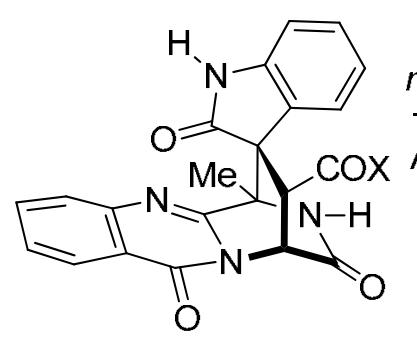

$\left\{\begin{aligned} 56 \times & =\mathrm{OH}(97 \%) \\ -57 \times & =\mathrm{SePh}\end{aligned}\right.$

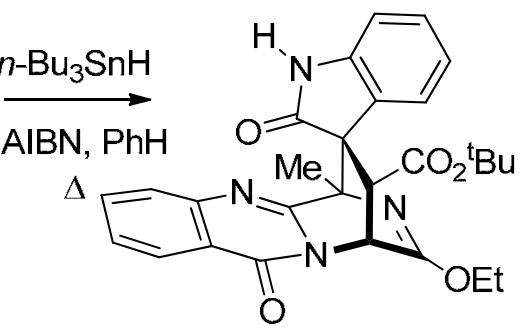

rac-7 (66\% from 56$)$

Scheme 5. Kende's first generation synthesis of racemic alantrypinone (rac-7).

In a first generation synthesis, dienophile 52 was treated with oxindole $\mathbf{5 3}$ (from isatin and $\mathrm{Ph}_{3} \mathrm{P}=\mathrm{CHCO}_{2}{ }^{\mathrm{t}} \mathrm{Bu}$ ) at room temperature to give a mixture of cycloadducts 54 and 55, separable by chromatography over silica gel. ${ }^{30}$ Isomer 54 was hydrolyzed (first the imidate with aqueous $\mathrm{HCl}$ and then the ester with trifluoroacetic acid) to give carboxylic acid 56. The acid was then 
converted to the corresponding selenoester 57, which was reduced under free radical conditions to provide racemic 7 .

In a second generation synthesis (Scheme 6), the Kende group simply used oxindole 13 (from isatin and trimethylsilylmethylmagnesium chloride according to a literature procedure) as the dienophile. The cycloaddition between $\mathbf{5 2}$ and $\mathbf{1 3}$ proceeded smoothly to provide $\mathbf{5 8}$ and 59 in $55 \%$ and $18 \%$ yields, respectively. The diastereomeric cycloadducts were separated and independently hydrolyzed to give racemic 7 (from 58) and 45 (from 59).

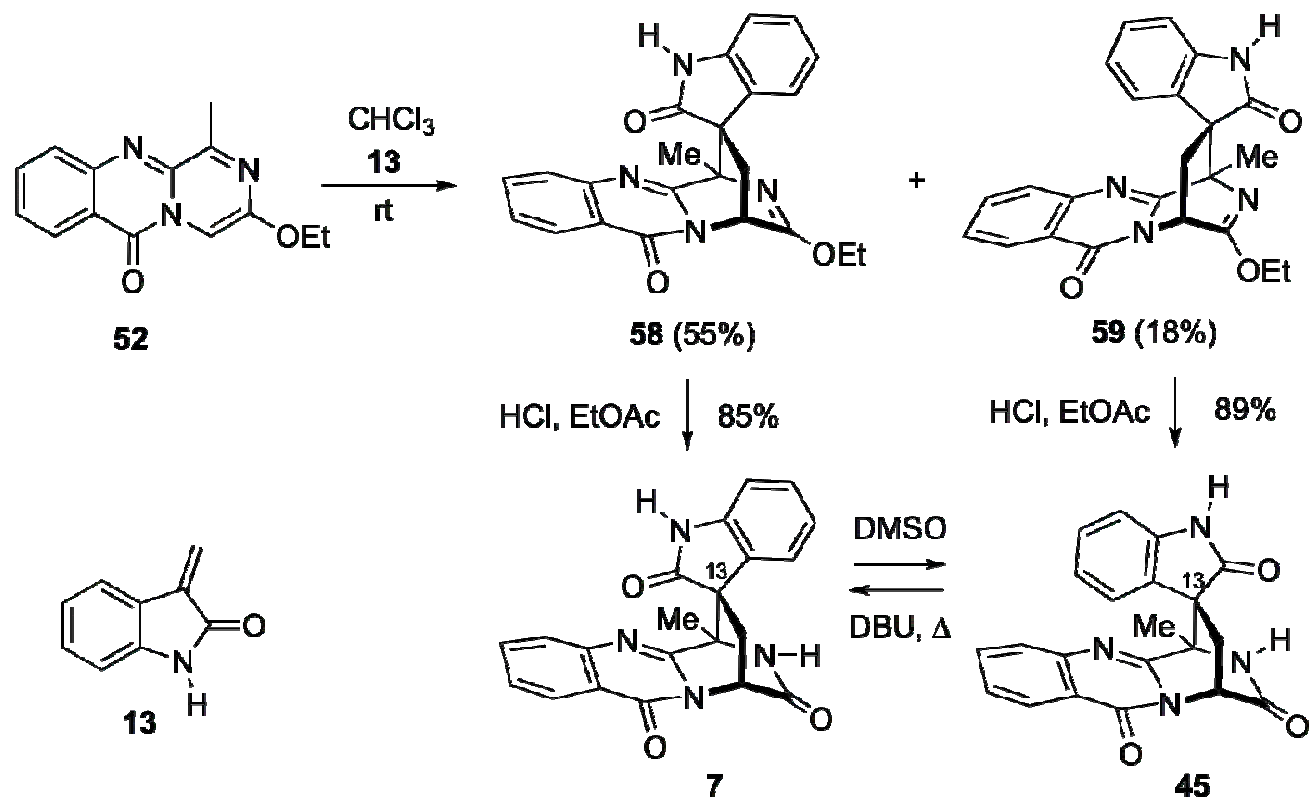

Scheme 6. Kende's second generation synthesis of racemic alantrypinone (rac-7).

Finally, the Kende group made the important observation that $\mathbf{7}$ and $\mathbf{4 5}$ can be interconverted under basic conditions. For example, heating either $\mathbf{7}$ or $\mathbf{4 5}$ in DMSO containing DBU provided an approximately 3:1 mixture of 7 and 45, respectively. This process requires epimerization at a quaternary carbon. The Kende group conclusively showed that this epimerization did not involve a retro-Diels-Alder process and suggested that instead, the epimerization involved an anionic retro-Mannich process. Regardless, this provides a means for achieving some degree of control over stereochemistry at C-13.

The Kende synthesis is quite versatile. Indeed a variation of this method was used for the extensive analog program, developed in the groups of Nishida, Arisawa, Ozoe and Meiji Seika Kaisha as described in Figure 9. ${ }^{21}$ A tactical change in this work was the use of microwave technology to expedite the synthesis of intermediate 50 (Scheme 7). Thus, anthranilic acid 46 was first coupled with $N$-Boc-L-alanine, followed by addition of ethyl glycinate and microwave irradiation for a short period of time, to provide 50 in 57\% yield. Microwave technology was introduced to the field by the Liu group in their syntheses of glyantrypine and related natural products. ${ }^{16 \mathrm{f}}$ An interesting aspect of this work was demonstration that cycloadduct $\mathbf{5 8}$ could be 
used to differentially functionalize the two secondary lactams in alantrypinone (Scheme 7). Thus, $\mathrm{N}$-alkylation of 58 followed by iminoether hydrolysis gave 60. On the other hand, $N$-sulfonation of oxindole 58, followed by iminoether hydrolysis, $\mathrm{N}$-alkylation, and removal of the benzenesulfonyl group from the oxindole nitrogen, gave $\mathbf{6 1 .}$

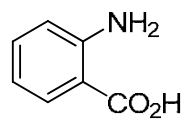

46

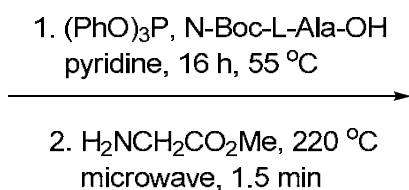

$57 \%$

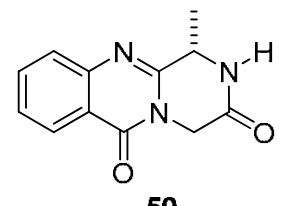

50

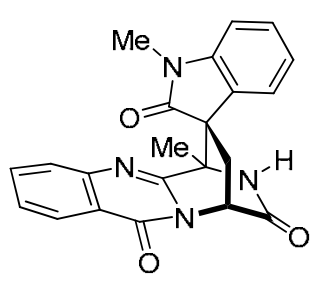

60

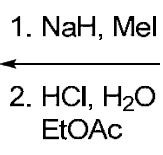

$72 \%$

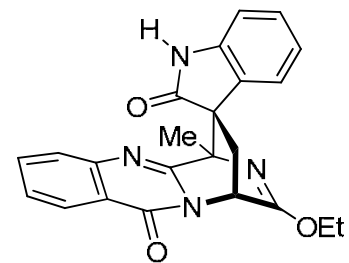

58

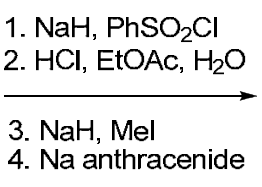

$18 \%$

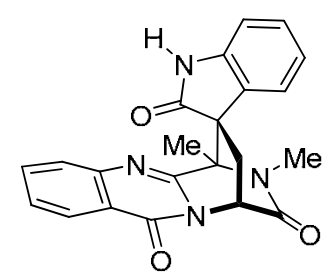

61

Scheme 7. Tactical improvements on the Kende synthesis and lactam differentiation.

The Avendaño group has described a formal synthesis of alantrypinone that intercepts the aforementioned ent-alantrypinone synthesis (Schemes 3 and 4) at the stage of indole 28. The synthesis proceeds through (-)-glyantrypine 14 as shown in Scheme 8. ${ }^{16 e, 31}$ D-Tryptophan methyl ester 36 was converted to diketopiperazine 63. Conversion of 63 to bis-lactim ether 64 was followed by a regioselective acylation with o-azidobenzoyl chloride to provide 65. An intramolecular Staudinger reaction (sometimes referred to as the Eguchi reaction when imides serve as the electrophilic component of the reaction) was used to provide (-)-glyantrypine $14 .^{32,33}$

(-)-Glyantrypine was converted to ent-28 as shown in Scheme 9. The indole and lactam nitrogens were first protected with Boc groups to provide 66. Methylenation at C-2 was accomplished using a procedure that resembles the Vilsmeier reaction and most likely proceeds through the enamine tautomer of $\mathbf{6 6}$. The resulting mixture of $\mathbf{6 7}$ and $\mathbf{6 8}$, was converted to ent-28 upon prolonged warming with trifluoroacetic acid. This reaction sequence gave a lower overall yield of ent-28 when the Boc protection step $(\mathbf{6 5} \rightarrow \mathbf{6 6})$ was omitted. The ent-28 prepared in this manner had a specific rotation ( $\mathrm{Na} \mathrm{D}$-line) equal in magnitude but opposite in sign to that reported for $\mathbf{2 8}$ and thus this work can be regarded as a formal synthesis of alantrypinone $\mathbf{7} .{ }^{34}$ 


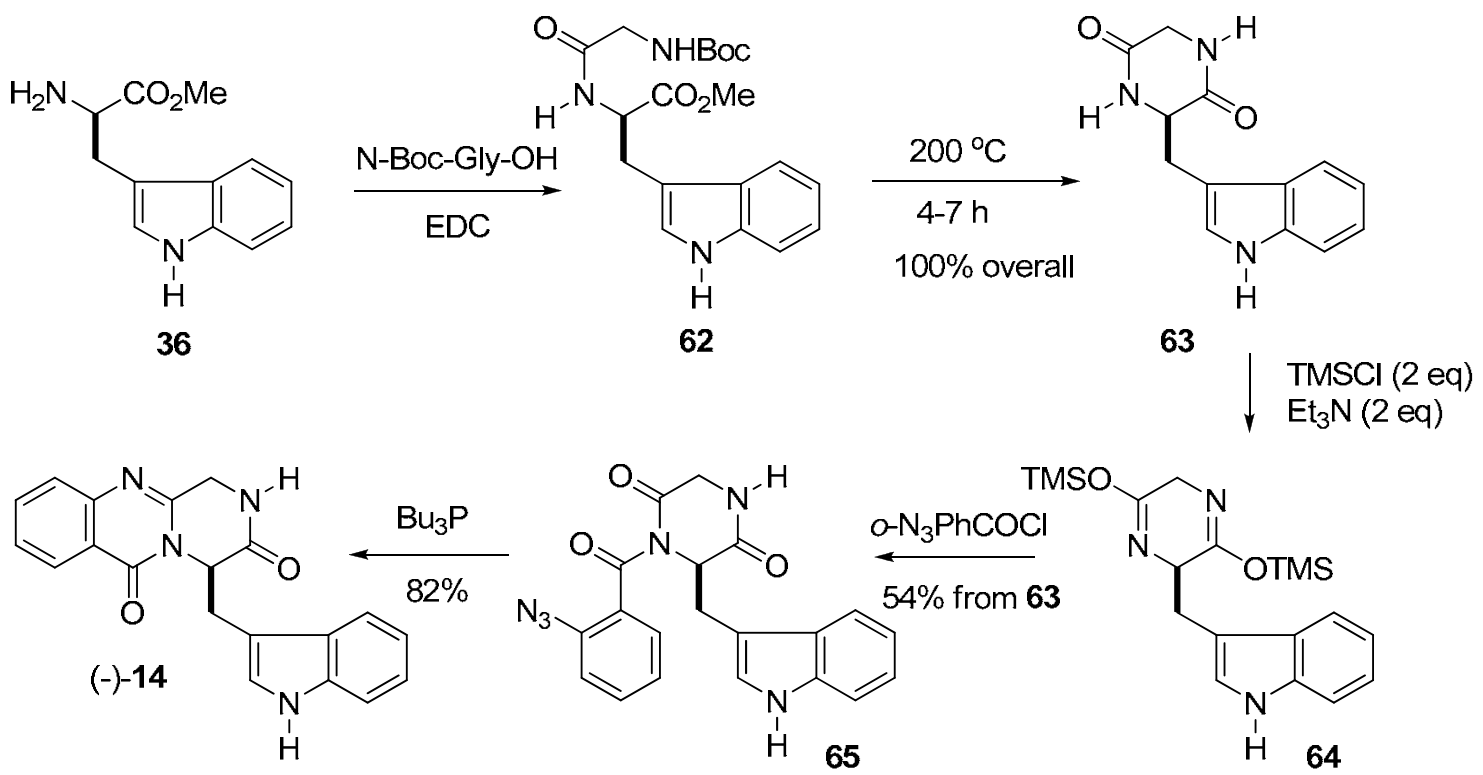

Scheme 8. Avendaño synthesis of (-)-glyantrypine 14 en route to alantrypinone.
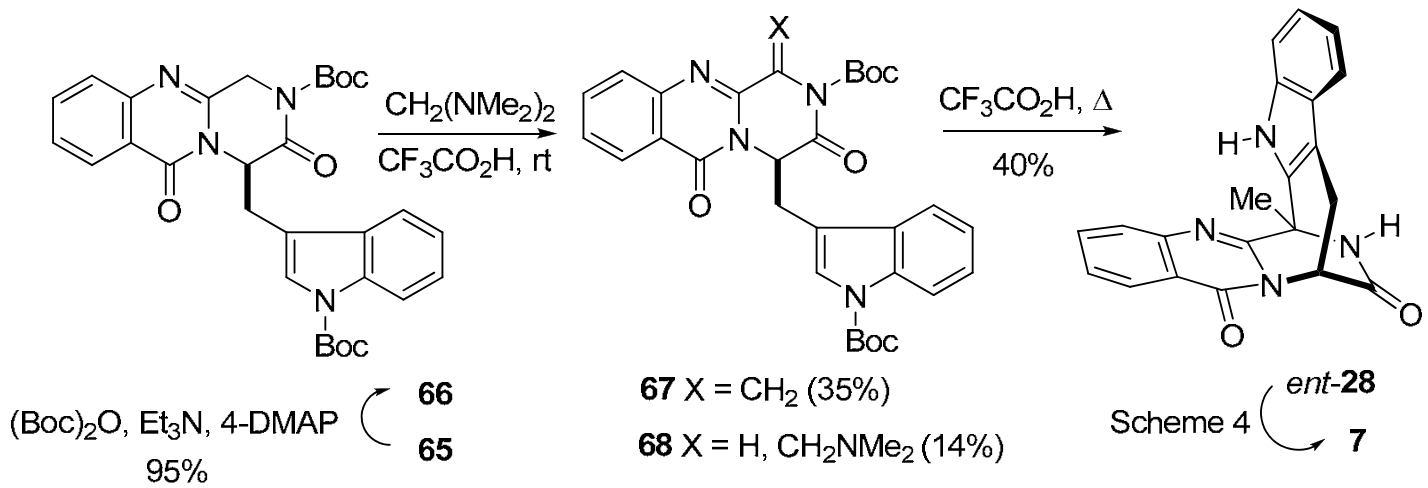

$67 X=\mathrm{CH}_{2}(35 \%)$

$68 X=\mathrm{H}, \mathrm{CH}_{2} \mathrm{NMe}_{2}(14 \%)$

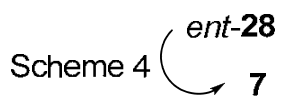

Scheme 9. Completion of Avendaño's formal synthesis of alantrypinone 7.

\subsection{Total synthesis of serantrypinone (8)}

The only synthesis of serantrypinone (to date) was reported in $2007 .^{35}$ The synthesis actually provided the enantiomer of the natural product (ent-8), but was important in that it resolved issues regarding the absolute configuration of this alantrypinone derivative (see Section 2.1 of this review and the primary literature for a complete discussion of the problem).

The synthesis mimicked the pathway defined by the first synthesis of alantrypinone and followed the chemistry described in Scheme 10. The original idea was use an electrophileinitiated cyclization of enamide 29 to afford compounds of type 69 in which the electrophile could be converted to the hydroxyl group required by serantrypinone. Attempts to epoxidize the exocyclic olefin of $\mathbf{2 9}$ failed, although it is still expected that this epoxide, if it could be prepared, would provide 69a upon treatment with acid. Treatment of $\mathbf{2 9}$ with iodine in THF provided 69b 
in $50 \%$ yield. ${ }^{36}$ Hydrogen iodide produced in this reaction, however, gave $28(20 \%)$ as an unwelcome side product. This problem was eliminated by including an HI trap (styrene oxide) in the reaction mixture. In this manner, the $\mathbf{2 8}$ was not formed and the yield of iodide $\mathbf{6 9 b}$ improved to $57-75 \% .{ }^{36}$ Conversion of the hindered iodo group to a hydroxyl group, either before or after conducting the indole-to-oxindole transformation, was not successful. Treatment of 29 with phenylselenenyl chloride gave selenide 69c in 78\% yield. The hope was that a seleno-Pummerer reaction could be used to convert the selenide to the corresponding alcohol via reduction of an intermediate aldehyde. Oxidation of 69c provided a mixture of diastereomeric selenoxides $\mathbf{7 0 .}$ Treatment of this mixture with acetic anhydride under typical Pummerer conditions provided a complex mixture of products from which $\mathbf{7 1}$ was isolated as the only identifiable material. Thus, this reaction sequence unexpectedly gave a compound that would clearly have value in a serantrypinone synthesis, albeit it low yield.

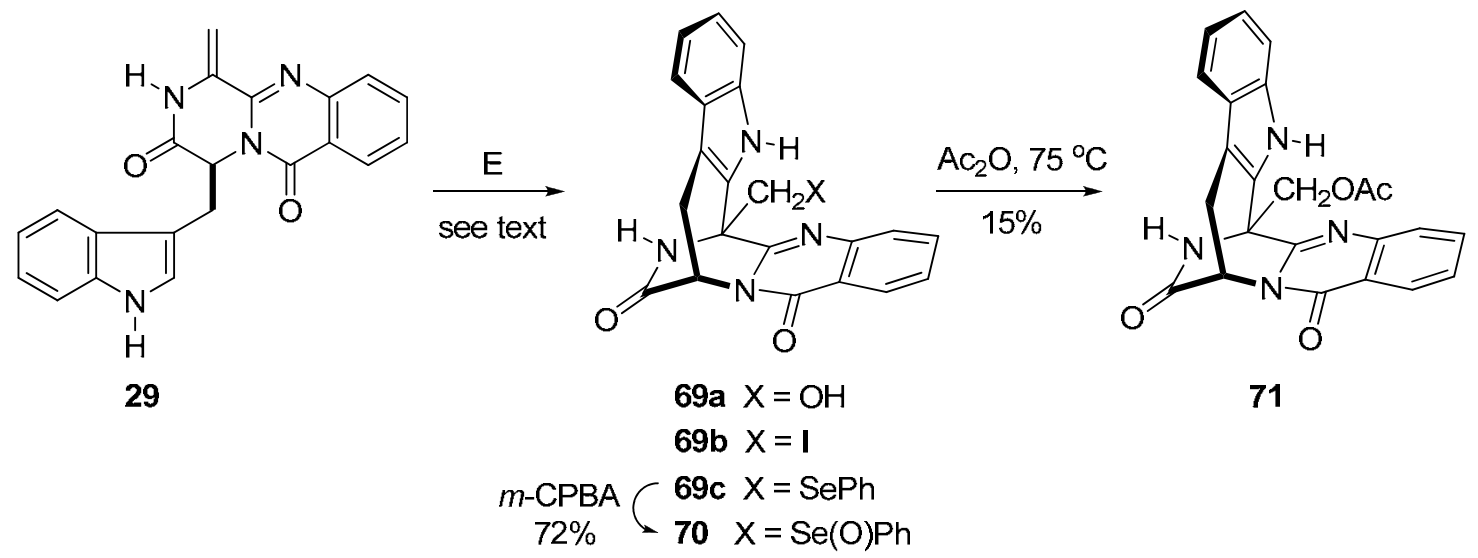

Scheme 10. Unexpected conversion of selenoxide $\mathbf{7 0}$ to acetate $\mathbf{7 1 .}$

It was speculated that $\mathbf{7 1}$ was formed by a series of events that involved (1) acetylation of the lactam nitrogen of $\mathbf{7 0}$ by acetic anhydride, (2) activation of the selenoxide via acylation of the oxygen by acetic anhydride, (3) intramolecular displacement of PhSeOAc from carbon by the $\mathrm{N}$ acetyl carbonyl group, and (4) capture of the resulting reactive intermediate followed by breakdown to give 71. This hypothesis suggested that the overall yield of 69c from 71 might be improved by intentional $\mathrm{N}$-acetylation of the selenide prior to oxidation and subjection of the selenoxide to an activating agent. This was accomplished as shown in Scheme 11.

Selective $N$-acylation of the lactam nitrogen (over the indole nitrogen) was accomplished using acetic anhydride. Oxidation of the resulting imide $\mathbf{7 2}$ gave a mixture of selenoxides, which was immediately treated with acetic anhydride to provide acetate 71 in $30-53 \%$ yields. When acetic anhydride- $d_{6}$ was used to acetylate 69c, and seventy equivalents of unlabelled acetic anhydride were used in the subsequent rearrangement, only a $\mathrm{CD}_{3}$ group appeared in the $\mathrm{O}$ acetyl group of 71. This provided strong evidence in support of the proposed mechanism. 

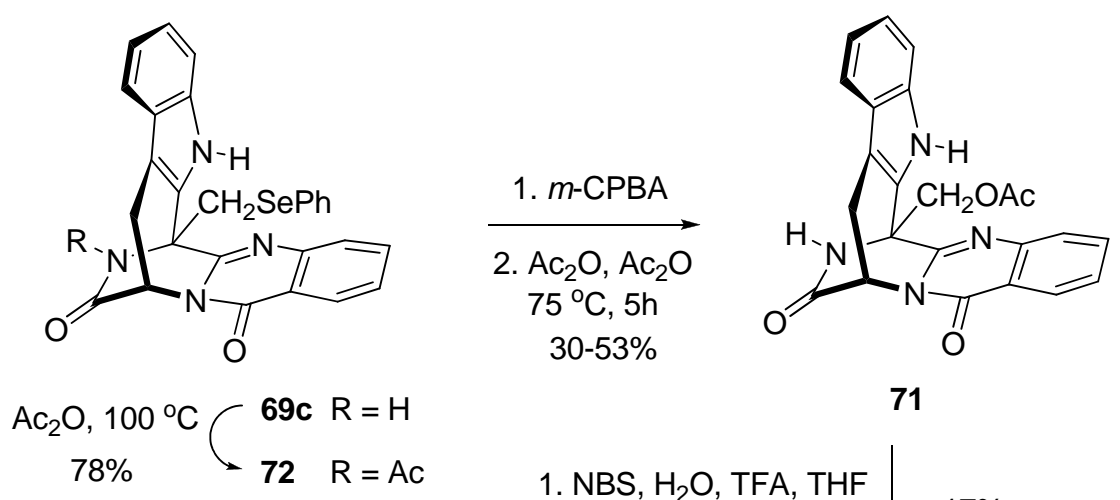

1. NBS, $\mathrm{H}_{2} \mathrm{O}$, TFA, THF

71

2. $\mathrm{H}_{2}, \mathrm{Pt} / \mathrm{C}$

$17 \%$

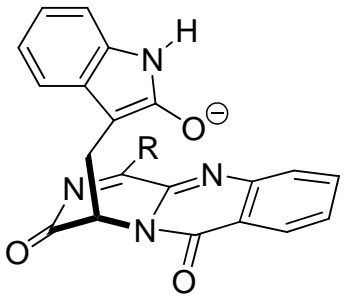

75

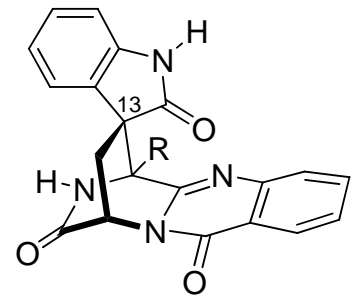

NaOMe, DMSO

$76 \%$

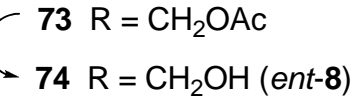

Scheme 11. Completion of ent-serantrypinone synthesis $(74=$ ent-8).

The synthesis was completed in a manner similar to that used to prepare ent-alantrypinone. Indole $\mathbf{7 1}$ was converted into oxindole $\mathbf{7 3}$ in the usual manner. The $\mathrm{C}-13$ epimer of $\mathbf{7 3}$ was also obtained from this process in $4 \%$ yield. Removal of the hindered acetate was accomplished using excess sodium methoxide in DMSO at room temperature over a period of 3 days. The rate of transesterification increased at elevated temperatures, but epimerization at $\mathrm{C}-13$, presumably via 75 as proposed for alantrypinone by Kende, was also observed. A head-to-head comparison (HPLC over a chiral support) of synthetic ent-serantrypinone with natural product isolated from Aspergillus terreus, and comparison of the $\mathrm{CD}$ spectrum of synthetic material with that reported for serantrypinone isolated from Penicillium thymicola, established the identity of the natural product.

\subsection{Total synthesis of lapatin B (9)}

Two syntheses of Lapatin B have been reported..$^{37,38}$ The first synthesis, from the Syntenta group in Switzerland, followed the Kende approach to alantrypinone and gave racemic material. The second synthesis followed the aforementioned routes to ent-alantrypinone and ent-serantrypinone and confirmed that the absolute configuration of lapatin B 9 is pseudoenantiomeric with alantrypinone $\mathbf{7}$ and serantrypinone 8.

The Syngenta synthesis began with the preparation of azadiene $\mathbf{7 6}$ from anthranilic acid 46 using a four-reaction sequence that applied a combination of the chemistry described in Schemes 
5 and 7 (Scheme 12). Reaction of 76 with methyleneoxindole 13 gave a 7:1 mixture of endo and exo cycloadducts (78 and 77, respectively). When the reaction was promoted by triflic acid, the ratio of endo and exo isomers changed to 1:1. Hydrolysis of iminoester 77 under mild conditions afforded amino acid hydrochloride 79, and more forcing conditions gave racemic lapatin B (rac9).

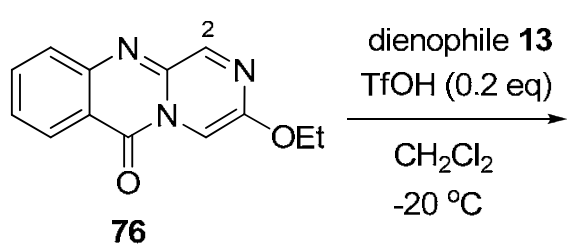

$$
20 \% \Leftrightarrow \begin{aligned}
& \text { 1. }(\mathrm{PhO})_{3} \mathrm{P}, \mathrm{N}-\mathrm{Boc}-\mathrm{Gly} \\
& \text { pyridine, } \Delta \\
& \text { 2. } \mathrm{H}_{2} \mathrm{NCH}_{2} \mathrm{CO}_{2} \mathrm{Et}-\mathrm{HCl} \\
& \text { microwave, } 210^{\circ} \mathrm{C} \\
& \text { 3. } \mathrm{Et}_{3} \mathrm{O}^{+} \mathrm{BF}_{4}^{-}, \mathrm{Na}_{2} \mathrm{CO}_{3} \\
& \text { 4. } \mathrm{DDQ}, \text { benzene, } \Delta
\end{aligned}
$$<smiles>Nc1ccccc1C(=O)O</smiles>

46

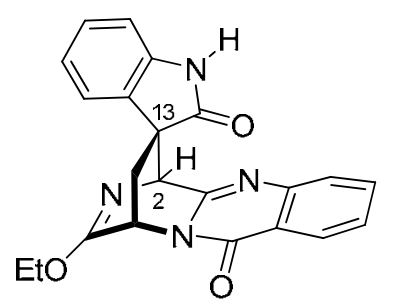

$77(\mathrm{exo} 32 \%)$<smiles>CC(CO)COO</smiles>

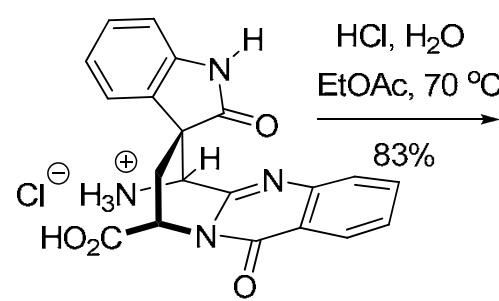

79

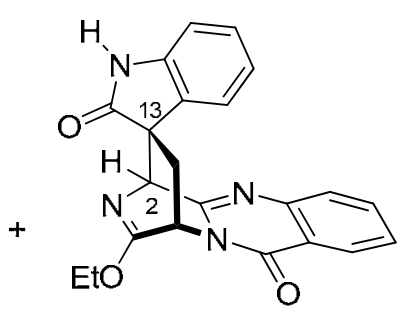

78 (endo $33 \%$ )

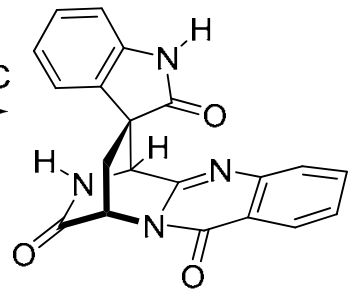

rac-9

Scheme 12. Syngenta synthesis of racemic lapatin B (rac-9).

The Syngenta group also investigated the effect of solvents and acid catalysts on the cycloaddition between azadiene 52 and dienophile 13 used in the Kende synthesis of alantrypinone (see Scheme 6). In the hands of the Syngenta group, this reaction gave a 1:2 mixture of exo and endo cycloadducts (58 and 59, respectively) in chloroform at room temperature. Computational studies suggested that the more polar the solvent, the greater should be the exo selectivity. In this regard it was found that use of acetonitrile as the solvent gave a 2:1 mixture of the exo 58 and endo 59 cycloadducts. In terms of Lewis acid promotion, it was found 52 and 13 reacted in the presence of one equivalent of $\mathrm{Eu}(\mathrm{fod})_{3}$ to provide only endo cycloadduct 59 in $73 \%$ yield. However, use of triflic acid as a catalyst ( 0.2 equivalents) gave exo cycloadduct 58 with high selectivity in 68\% yield. The difference of behavior between azadienes 76 (less stereoselective) and 52 (more stereoselective) indicates the size of the C-2 substitutent influences stereoselectivity. In a practical sense, these observations provided a tactical improvement to the Kende alantrypinone synthesis and enabled the first synthesis of lapatin B. 

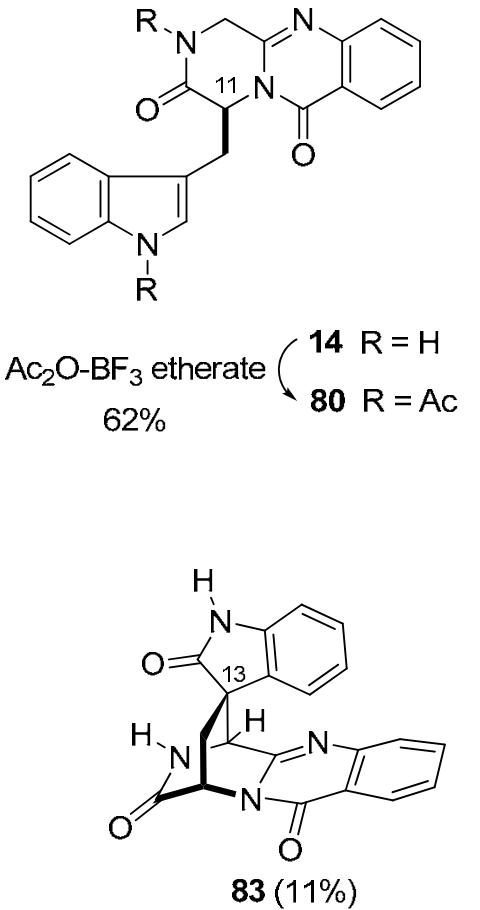
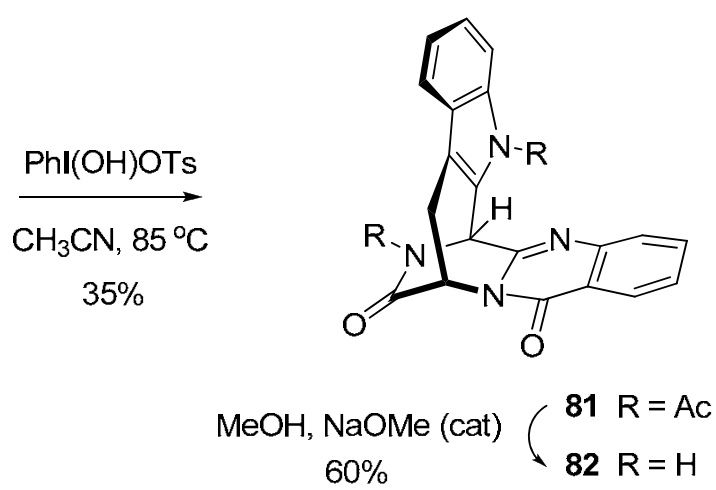

1. $\mathrm{NBS}, \mathrm{THF}-\mathrm{TFA}-\mathrm{H}_{2} \mathrm{O}(1: 2: 1)$
2. $\mathrm{H}_{2}, \mathrm{Pt} / \mathrm{C}, \mathrm{ACOH}, \mathrm{NaOAC}$

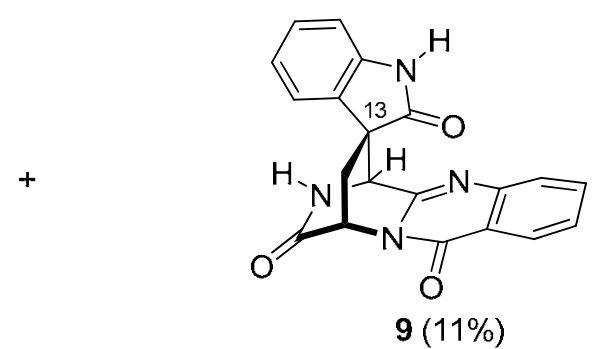

Scheme 13. Enantioselective synthesis of lapatin B 9.

The first enantioselective synthesis of lapatin B is described in Scheme $13 .^{38}$ The synthesis began with the preparation of (+)-glyantrypine 14 from L-tryptophan methyl ester using either the method of Ganesan, or the modification of the Ganesan-Mazurkiewicz cyclization shown in Scheme 3, to accomplish the critical imino-benzoxazine-to-quinazolinone rearrangement. From a tactical standpoint, the Ganesan procedure gave slightly better yields. ${ }^{16 \mathrm{c}}$ Heating 14 with excess of acetic anhydride in the presence of pyridine, with 4-dimethylaminopyridine as a catalyst, gave 80 in $81 \%$ yield, but with racemization at C-11. Use of acidic acetylation conditions, however, provided 80 without any epimerization at C-11 (Scheme 13). Oxidative cyclization of 80 was accomplished using Kosar's reagent [PhI(OH)OTs] in acetonitrile to give indole $\mathbf{8 1}$ in 35\% yield. The oxidation portion of this reaction was modeled after observations reported by the Avendaño group during the course of their studies of the chemistry of pyrazino[2,1-b]quinzaline-3,6diones. $^{39}$ Methanolysis of the acetyl groups under basic conditions gave 82. The indole-tooxindole rearrangement, followed by hydrogenolysis of extraneous aryl bromides, completed the synthesis of lapatin B 9 and also provided the C-13 epimer of lapatin B 83 in low yields.

\subsection{Approaches to spiroquinazoline (1)}

Several approaches to spiroquinazoline have been reported but none have succeeded to date. This section will briefly review approaches that have been attempted or are underway.

One failed approach to spiroquinazoline is described in Schemes $14-16 .{ }^{40,41}$ The plan (Scheme 14) was to generate an $N$-acyliminium ion of type $\mathbf{8 5}$ by electrophile initiated ionization 
of an N,S-acetal of type 84. Scheme 14 depicts a methyl cation equivalent (iodomethane for example) as the S-activating group, but a number of alternatives were imagined. It was hoped that 85 might cyclized with $\mathrm{C}-3$ of the indole behaving as a nucleophile. Furthermore it was hoped that the resulting $N$-acyliminium ion $\mathbf{8 6}$ might be captured by the glycine-derived nitrogen to provide spiroquinazoline $\mathbf{1}$ after deprotection of the nitrogens.<smiles>[R]NCC(=O)n1cc(C[C@@H]2C(=O)N3CCSC3(C)c3nc4ccccc4c(=O)n32)c2ccccc21</smiles>
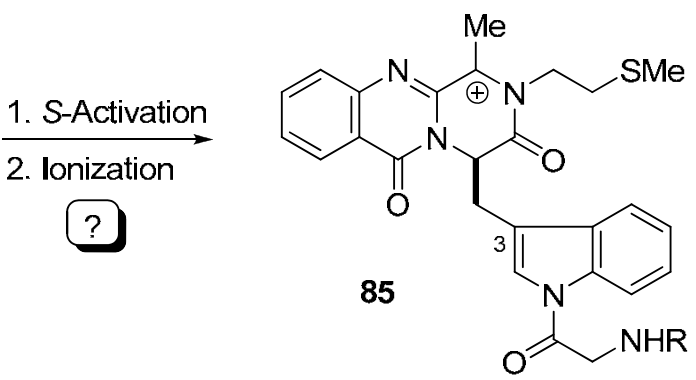

?] Cyclization

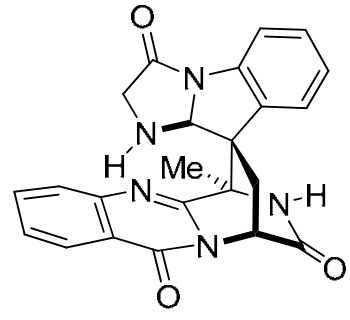

1

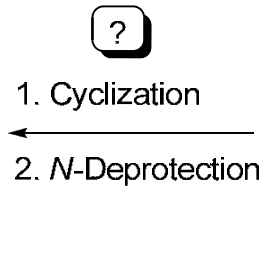

1. Cyclization

2. N-Deprotection

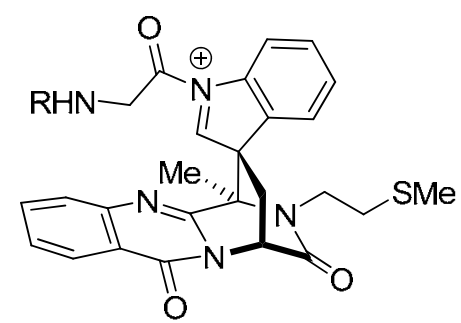

86

Scheme 14. Plan for conversion of $\mathbf{8 4}$ to spiroquinazoline $\mathbf{1}$ via a cyclization cascade.

The plan did not work, but unveiled chemistry of some relevance to the field. Racemic $\mathbf{8 8}$ was prepared from the known quinazolinone $\mathbf{8 7}$ as indicated in Scheme 15. Attempts to activate 88 by alkylation or with other electrophiles such as mercuric triflate gave no identifiable products. Activation of the sulfur via oxidation to sulfoxide $\mathbf{8 9}$ led to some interesting chemistry. Warming 89 with trifluoroacetic acid gave ring expansion product 92 in a high yield. It was proposed that this transformation was mechanistically analogous to the Morin rearrangement of penams to cephams. ${ }^{42}$ In fact, it had been hoped that the presumed intermediate $N$-acyliminium ion 91 might initiate the double cyclization sequence outlined in Scheme 14, but this was not the case; 92 was a dead end as studies with $\mathrm{CF}_{3} \mathrm{CO}_{2} \mathrm{D}$ indicated that it was not protonated to give $\mathbf{9 1}$. 
<smiles></smiles><smiles>CC(C)(C)OC(=O)NCC(=O)n1cc(CC2C(=O)N3CCSC=C3c3nc4ccccc4c(=O)n32)c2ccccc21</smiles>

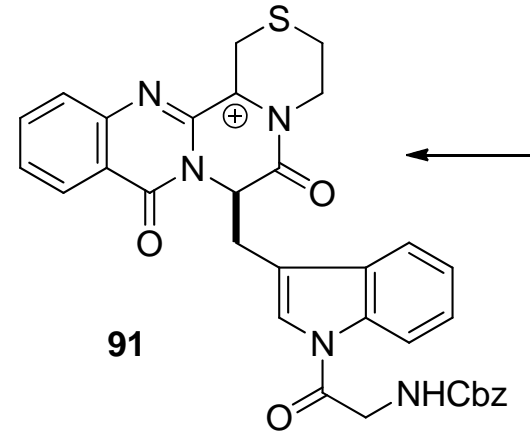<smiles>C=C1c2nc3ccccc3c(=O)n2C(Cc2cn(C(=O)CNC(=O)O)c3ccccc23)C(=O)N1CCS</smiles>

Scheme 15. Failure to capture a possible intermediate cation with an $N$-acylated indole.

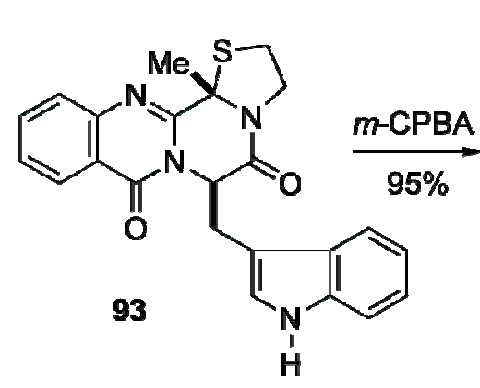

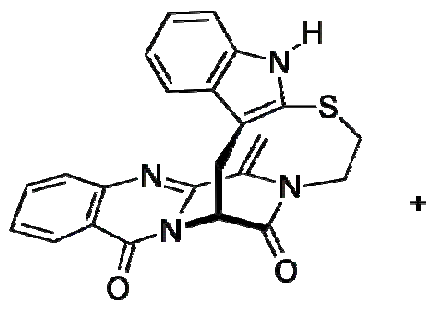

$98(14-21 \%)$

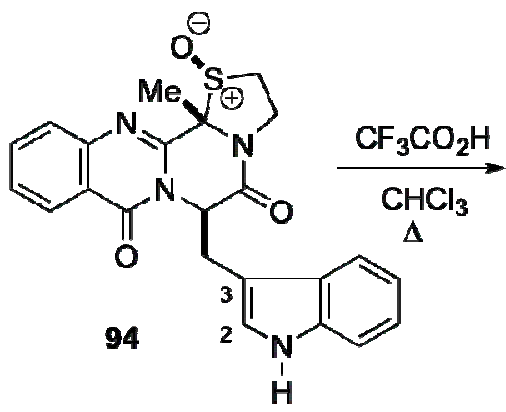

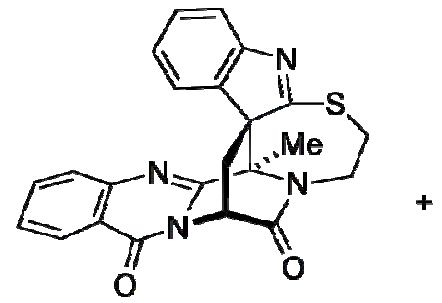

$97(22-25 \%)$<smiles></smiles>

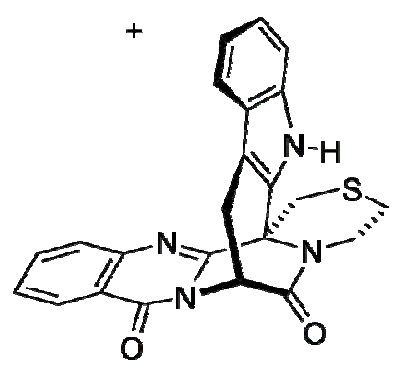

$96(21-35 \%)$

Scheme 16. Acid promoted chemistry of 94 provides structures related to the spiroquinazolines. 
The result shown in Scheme 15 indicated that an acylated indole was not a good enough nucleophile to capture an intermediate cation. This observation resulted in examination of sulfoxide 94, prepared from 93, the penultimate intermediate in the synthesis of $\mathbf{8 8}$. Sulfoxide 94 gave a number of products 95-98 upon treatment with trifluoroacetic acid (Scheme 16). Three of the products 96-98 appear to be derived from the indole capturing a reactive intermediate analogous to deacylated 91. It is also notable that isomers $\mathbf{9 7}$ and $\mathbf{9 8}$ are in equilibrium under the reaction conditions. Whereas the reader should consult the primary literature for a mechanistic interpretation of the results shown in Scheme 16, the results provide evidence that at least a portion of the plan outlined in Scheme 14 can be realized.

Another approach to spiroquinazoline would be to pass through alantrypinone as an intermediate. This plan would require methodology for the conversion of an oxindole to an imidazoloindoline. Two methods for accomplishing this task have been reported (Scheme 17). ${ }^{43}$ One method relies on the Eguchi reaction $(\mathbf{9 9} \rightarrow \mathbf{1 0 0} \rightarrow \mathbf{1 0 1} \rightarrow \mathbf{1 0 2})^{33}$ and the other on a rather unusual imide reduction $(\mathbf{9 9} \rightarrow \mathbf{1 0 3} \rightarrow 104 \rightarrow 105 \rightarrow 102)$.

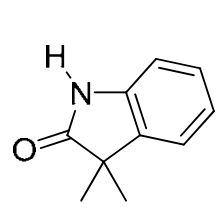

99

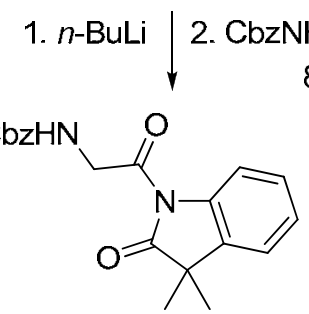

103

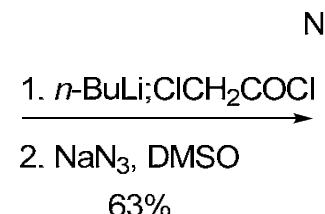

$63 \%$

100

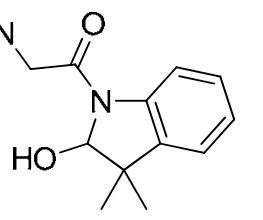

104 $88 \%$

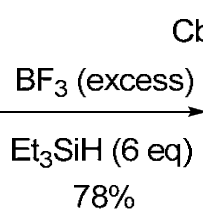

$78 \%$
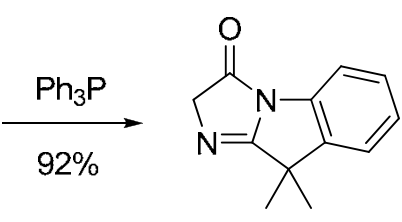

101
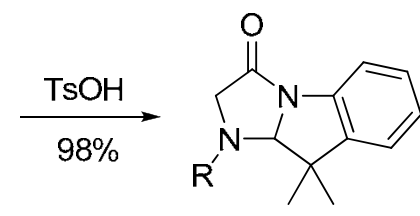

$\mathrm{H}_{2}, \mathrm{Pd} / \mathrm{C}$ $100 \%$
$102 \mathrm{R}=\mathrm{H}$

$105 \mathrm{R}=\mathrm{Cbz}$

Scheme 17. Model studies for conversion of alantrypinone to spiroquinazoline.

Both methods, however, failed to convert ent-alantrypinone to spiroquinazoline (Scheme 18). ${ }^{44}$ It was not possible to prepare 106 using the procedure described in Scheme 17. Whereas acylation of the nitrogen was possible, treatment of the resulting chloride with sodium azide gave only ent-alantrypinone. It was possible to prepare 106 in $71 \%$ yield by using $p$-nitrophenyl $\alpha$ azidoacetate as the acylating agent, but reaction of 106 with $\mathrm{Ph}_{3} \mathrm{P}, n-\mathrm{Bu}_{3} \mathrm{P}$ or $\left(\mathrm{Me}_{2} \mathrm{~N}\right)_{3} \mathrm{P}$ gave only ent-7 via a deacylation reaction. The fate of the azido group in these reactions was not determined. It was also possible to prepare glycine derivative $\mathbf{1 0 7}$ in $70 \%$ yield using the procedure set forth in Scheme 17. Treatment of this imide with $\mathrm{BF}_{3} \bullet \mathrm{Et}_{3} \mathrm{SiH}$ led to a slow reaction that once again provided ent-7 as the only identifiable product. A detailed explanation for the 
difference in behavior of the model systems shown in Scheme 17 and 106/107 has been set forth. ${ }^{44}$ Without going into details, it was proposed that a combination of steric effects and conformational differences are responsible for the observed behavior of these systems.

A model system based on anthracene derivatives was examined as an afterthought (Scheme 18). Acylation of lactam 108 was accomplished as described in Scheme 17, but conversion of the chloride to the corresponding azide failed. Only deacylation to return 108 was observed. Acylation of the anion derived from 108 using $p$-nitrophenyl $\alpha$-azidoacetate as the electrophile, however, gave the desired azide in $66 \%$ yield. Treatment of the azide with triphenylphosphine in benzene at room temperature, gave a 37\% yield of 109. Reduction of 109 using the standard Borch conditions provided a 78\% yield of a 5:1 mixture of diastereomeric $N, N$-acetals from which each isomer was isolated in reduced yield. The stereochemistry of these isomers was easily determined by nOe studies.
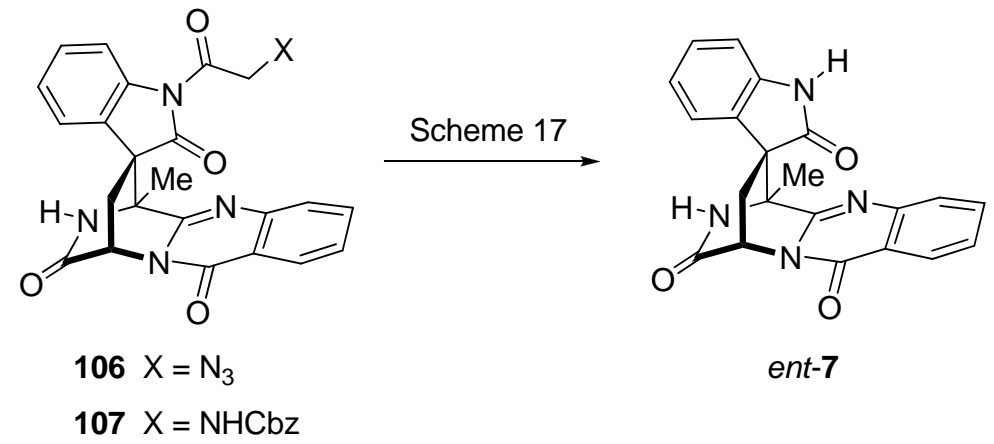

ent-7

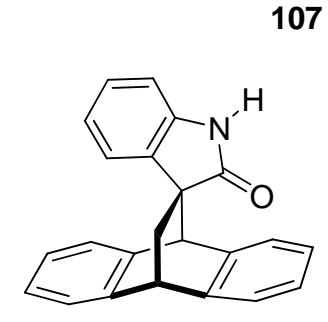

108

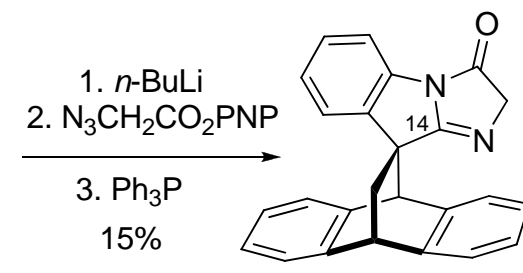

109

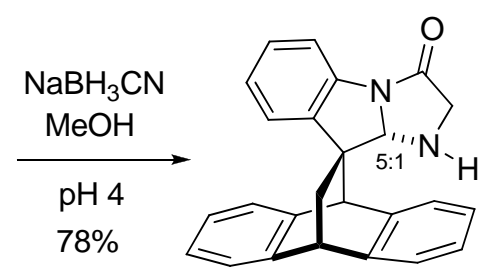

110

Scheme 18. More model studies for conversion of alantrypinone to spiroquinazoline.

Thus results shown in Scheme 18 seem consistent with the failed attempts to use this chemistry to convert alantrypinone to spiroquinazoline. The yield of the Eguchi cyclization is low and $\mathrm{N}$-deacylation problems persist throughout the conversion of 108 to 109. Furthermore compound 109 was unstable and was converted completely to anthracene upon standing in $\mathrm{CDCl}_{3}$ at room temperature for a day (NMR tube experiment). Finally, the stereochemical course of the reduction of $\mathbf{1 0 9}$ to $\mathbf{1 1 0}$ does not bode well for obtaining the C-14 stereochemistry required by spiroquinazoline using this methodology ( $\mathrm{C}-\mathrm{H}$ bond formation last). This result suggests that final $\mathrm{C}-\mathrm{N}$ bond construction might be more desirable in related approaches to spiroquinazolines. In this regard, it has been observed that imine 11 reacts with the acid chloride of $N$-Ts-glycine 112 to give a 62\% yield of 111 (Scheme 19). ${ }^{45}$ Thus, if the conversion of 
alantrypinone to $\mathbf{1 0}$ can be accomplished, variations of this approach might provide access to spiroquinzoline $\mathbf{1}$ and possibly alkaloids 3-5.

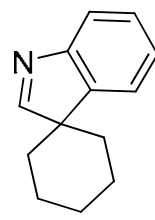

11
$\mathrm{TsNHCH} \mathrm{COCl}_{2}$ (112)

xylene, $\Delta$

$62 \%$

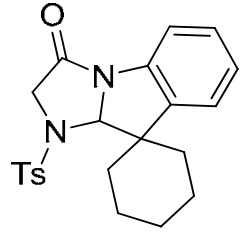

111

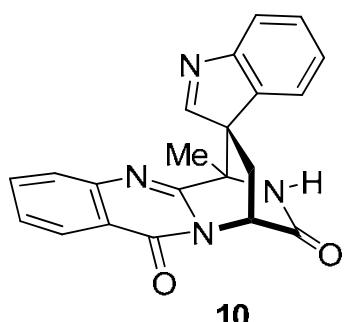

10

Scheme 19. Conversion of imine 11 to $N, N$-acetal 111.

An approach to spiroquinazoline that is very different from either the cycloaddition or $N$ acyliminium ion routes has recently been described (Schemes 20-22). ${ }^{46}$ The plan (Scheme 20) was to prepare members of the spiroquinazoline family of alkaloids from an intermediate of type 113 with a focus on construction of the $\mathrm{N}-\mathrm{C}-17$ bond. Intermediates of type $\mathbf{1 1 3}$ were to be prepared from diketopiperazine derivatives of type 114. An intramolecular $S_{N} 2^{\prime}$ reaction of a substrate of type $\mathbf{1 1 5}$ was to provide 114. Use of this type of process had precedence in the Williams group approach to the brevianamides and paraherquamides. ${ }^{47}$
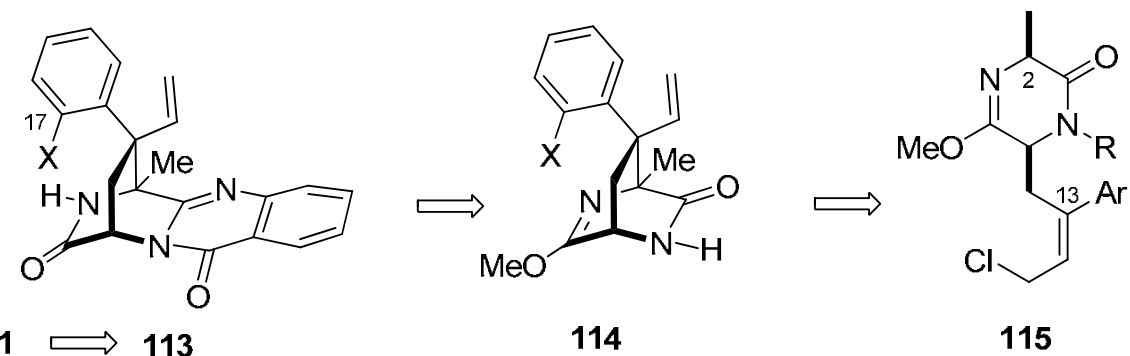

Scheme 20. Chen-Williams approach to synthesis of spiroquinazolines.

The approach began with development of an enantioselective route to functionalized $\alpha$-amino acids. $^{48}$ This method was used to prepare 116 in two steps $(62 \%$ yield) from $N$-(tertbutoxycarbonyl)-L-iodoalanine methyl ester (Scheme 21). The Boc group was removed and replaced with a p-nosyl group. Alkylation of the sulfonamide with 3,4-dimethoxybenzyl bromide, removal of the nosyl group and acylation of the resulting amine with $\mathrm{N}$-Fmoc-Lalanine, and removal of the Fmoc group, completed the synthesis of diketopiperazine 117 (32\% overall from 116). Pd-mediated coupling of the vinylstannane with $\mathrm{Ph}_{2} \mathrm{I}^{+} \mathrm{Cl}^{-}$introduced the incipient C-13 phenyl group. Conversion of the secondary lactam into the imino ether, reduction of the ester, and conversion of the resulting allylic alcohol to a chloride gave cyclization substrate 118 (46\% overall from 117). Cyclization of 118 gave separable diketopiperazine 
derivatives 119 and 120. It is notable that the $\mathrm{Pd}$-mediated arylation $\left(\mathrm{SnMe}_{3} \rightarrow \mathrm{Ph}\right)$ was also used to introduce $o$-bromophenyl and $o$-nitrophenyl groups, but the subsequent intramolecular $\mathrm{S}_{\mathrm{N}} 2^{\prime}$ reactions were unsuccessful. The $N$-aryl group was removed from 120 to provide 121.
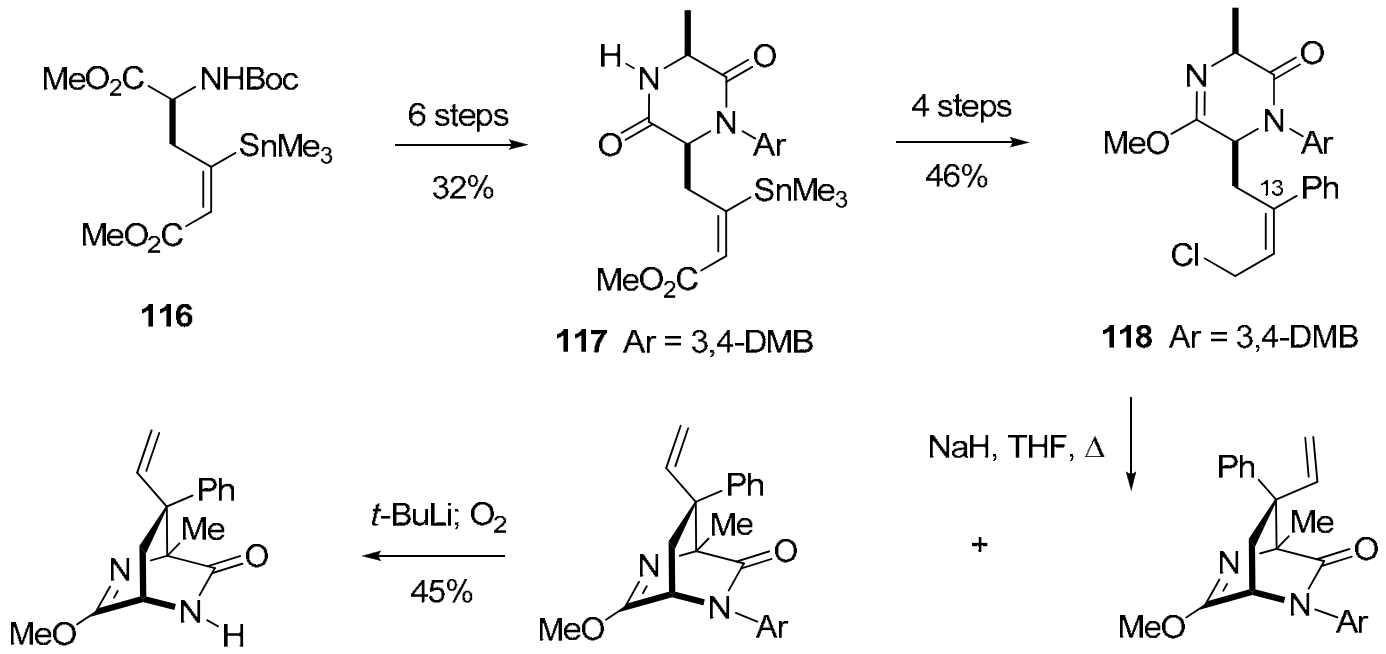

121

$120 \mathrm{Ar}=3,4-\mathrm{DMB}(39 \%)$

$119 \mathrm{Ar}=3,4-\mathrm{DMB}(13 \%)$

$46 \% \downarrow \begin{gathered}\text { 1. KHMDS; } \mathrm{o}-\mathrm{N}_{3} \mathrm{PhCOCl} \\ \text { 2. } \mathrm{Bu}_{3} \mathrm{P}\end{gathered}$

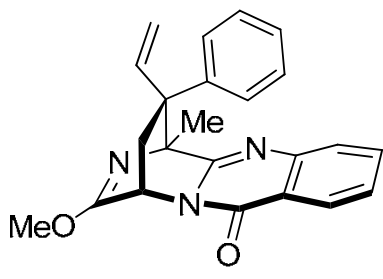

122
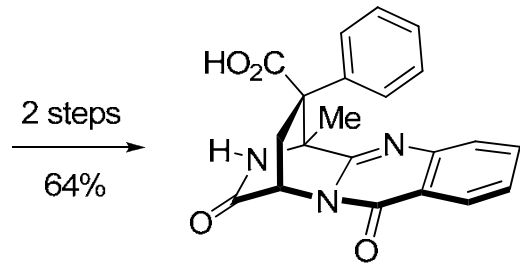

123

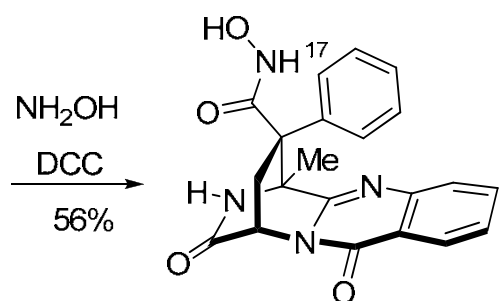

124

Scheme 21. Synthesis of hydroxamic acid 124 from amino acid 116.

Application of the Eguchi protocol gave quinazolinone 122. Ozonolysis of the vinyl group was followed by oxidation of the resulting aldehyde, concomitant with hydrolysis of the imino ether, to give carboxylic acid 123. The acid was converted to hydroxamic acid 124, but construction of the $\mathrm{N}-\mathrm{C}-17$ bond has not yet been accomplished. Overall this is a creative and enantioselective approach to the spiroquinazolines and it is unfortunate that $O$-substituted aromatics did not undergo the key cyclization reaction.

\section{Conclusions}

What is known and what is not known about the structures of the spiroquinazoline-type alkaloids reported thus far? The carbon skeletons of nine members of this family are secure 1-9. 
Stereochemical aspects of several of these natural products also seem secure 6-9. The relative and absolute stereochemistry assigned to lapatin A 2 appears to be correct. It is notable that the stereochemistry at the $N, N$-acetal (C-14) in 2 (determined by NMR) is the opposite of that found in 6 (determined by X-ray) and 3-5 (determined by NMR). The absolute stereochemistry of $\mathbf{1}$ and 3-5 has yet to be determined.

What is known about the biosynthesis of the spiroquinazoline-type alkaloids? No experiments have been directed toward unraveling how nature makes these alkaloids. This may be interesting to study. Some of the alkaloids appear to incorporate D-tryptophan while others incorporate L-tryptophan. Some appear to incorporate D-amino acids in the C-14-indoline nitrogen bridge, while others appear to incorporate L-amino acids. It is not known if posttranslational epimerizations play a role in the apparent incorporation of D- or L-series amino acids. Feeding studies are needed to sort out the possibilities. Are there any trends? It appears that compounds, in which a hydrogen appears at C-2 formally incorporate L-tryptophan 2, 6 and 9. The two cases where non-hydrogen atoms appear at C-2 formally incorporate D-tryptophan 7 and 8. There are not enough data points to be sure of anything, but if this correlation holds, spiroquinazoline $\mathbf{1}$ and alkaloids 3-5 will formally incorporate D-tryptophan.

How about biological activity? It appears that the spiroquinazolines display a variety of biological activities that have attracted the attention of those interested in analgesics or insecticides. None of the activities, however, seems to be high enough to be of serious interest at this time.
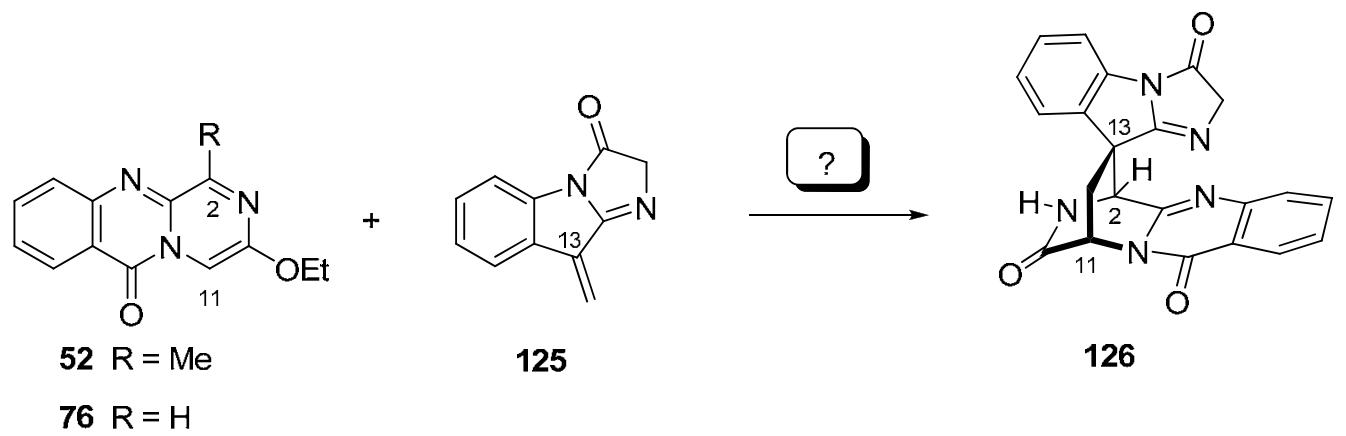

Scheme 22. A possible variation on the Diels-Alder theme.

What about synthesis? Two versatile routes to the alkaloids lacking a $\mathrm{C}-14-\mathrm{N}$ bridging amino acid 7-9 have been developed. The most practical route involves Diels-Alder chemistry. This provides racemic material. A route that involves an intramolecular $N$-acyliminium ion cyclization seems less practical. This route might be improved by focusing on generation and cyclization of intermediates of type $\mathbf{7 5}$ under basic conditions. This would require oxidation of the tryptophan-derived indole to an oxindole prior to cyclization, and would also require $N$ acylimine generation under basic conditions. It is notable that the $N$-acyliminium ion cyclization 
route does provide single enantiomers that are a function of the enantiomer of tryptophan used as a starting material.

No synthesis of an alkaloid containing an amino acid bridge between C-14 and nitrogen has been accomplished. Several attempts to append a glycine bridge to alantrypinone have failed. One route that still has promise would involve reduction of the oxindole of alantrypinone (or lapatin B), followed by fusing the bridging amino acid to the resulting imine 10. An observation that model compound $\mathbf{1 0 9}$ readily provides anthracene suggests that it might be worthwhile to study Diels-Alder reactions of dienophiles such as $\mathbf{5 2}$ and $\mathbf{7 6}$ with as yet unknown dieneophiles of type 125 (Scheme 22). Finally, fusion of the Diels-Alder approach with ideas for late N-C-17 bond formation proposed by Chen and Williams would provide another possible route to amino acid bridged spiroquinazolines.

It is the author's opinion that much has been done in this area of natural products chemistry, but a number of logical and interesting goals have yet to be accomplished. The author for one will be interested to see what transpires during the next decade.

\section{Acknowledgements}

I acknowledge the National Institutes of Health for supporting our early work in this area, and contributions of the late Dr. Nabi Magomedov for getting us started in the field of spiroquinazoline chemistry. ${ }^{49}$ I thank Mr. Steven Walker, Dr. Gabriel Oba, Dr. Angela Winstead and Ms. Grace Mbogo for continuing our work in the area, and Dr. Judith Gallucci for several useful crystal structures. I also want to thank Professor Yoshihisa Ozoe for evaluating the insect GABA receptor binding properties of ent-alantrypinone, ent-serantrypinone and lapatin B and providing an authentic sample of serantrypinone, Dr. Tomas Larsen for providing an authentic sample of alantrypinone and Dr. Stafford McLean for conducting SP NK-1 binding inhibition studies of several intermediates prepared during the course of our research. I also want to thank Professor Edson Rodriguez-Filho, Professor Robert Williams, Professor Yoshihisa Nozoe and Dr. Olivier Loiseleur for providing information used to prepare this review. Finally I want to acknowledge the encouraging manner, in which Professor Jim Cook served as my laboratory teaching assistant many years ago at the University of Michigan.

\section{References and Notes}

1. Barrow, C. J.; Sun, H. H. J. Nat. Prod. 1994, 57, 471.

2. For a review of quinazolinone natural products see Mhaske, S. B.; Argade, N. P. Tetrahedron 2006, 62, 9787.

3. Larsen, T. O.; Petersen, B. O.; Duss, J. Ø.; Sørensen, D.; Frisvad, J. C.; Hansen, M. E. J. Nat. Prod. 2005, 68, 871. 
4. Barros, F. A. P.; Rodrigues-Filho, E. Biochem. Sys. Ecology 2005, 33, 257.

5. Koyama, N.; Inoue, Y.; Sekine, M.; Hayakawa, Y.; Homma, H.; Omura, S.; Tomoda, H. Org. Lett. 2009, 10, 5273.

6. Larsen, T. O.; Frydenvang, K.; Frisvad, J. C.; Christophersen, C. J. Nat. Prod. 1998, 61, 1154.

7. (a) Kuriyama, T.; Kakemoto, E.; Takahashi, N.; Imamura, K.; Oyama, K.; Suzuki, E.; Harimaya, K.; Yaguchi, T.; Ozoe, Y. J. Agric Food Chem. 2004, 52, 3884. (b) Ozoe, Y.; Takahashi, N.; Oyama, K.; Imamura, K.; Harimaya, T.; Yaguchi, T. Japanese Patent 142785, 2002.

8. Larsen, T. O.; Svendsen, A.; Smedsgaard, J. Appl. Environ. Micro. 2001, 67, 3630.

9. Ariza, M. R.; Larsen, T. O.; Peterson, B. O.; Duus, J. Ø.; Christophersen, C.; Barrero, A. F. J. Nat. Prod. 2001, 64, 1590.

10. (a) Personal communication from Professor Edson Rodrigues-Filho. For spectra of 11 see (b) Rodriguez, J. G.; Benito, Y.; Temprano, F. J. Heterocyclic Chem. 1985, 22, 1207 and (c) Linnepe, P.; Schmidt, A. M.; Eilbracht, P. Org. Biomol. Chem. 2006, 4, 302.

11. For a review of natural product synthesis by retro mass spectral analyses see Kametani, T.; Fukumoto, K. Accts. Chem. Res. 1976, 9, 319.

12. Marahiel, M. A.; Stachelhaus, T.; Mootz, H. D. Chem. Rev. 1997, 97, 2651.

13. Penn, J.; Mantle, P. G.; Bilton, J. N.; Sheppard, R. N. J. Chem. Soc., Perkin Trans. 1 1992, 1495.

14. Penn, J.; Purcell, M.; Mantle, P. G. FEMS Microbiol. Lett. 1992, 92, 229.

15. (a) Numata, A.; Takahashi, C.; Matsushita, T.; Miyamoto, T.; Kawai, K.; Usami, Y.; Matsumura, E.; Inoue, M.; Ohishi, H.; Shingu. T. Tetrahedron Lett. 1992, 33, 1621. (b) Takahashi, C.; Matsushita, T.; Doi, M.; Minoura, K.; Shingu, T.; Kumeda, Y.; Numata, A. J. Chem. Soc., Perkin Trans. 1 1995, 2345.

16. (a) He, F.; Snider, B. B. Synlett 1997, 483. (b) He, F.; Snider, B. B. J. Org. Chem. 1999, 64, 1397. (c) Wang, H.; Ganesan, A.; J. Org. Chem. 1998, 63, 2432. (d) Wang, H.; Ganesan, A. J. Org. Chem. 2000, 65, 1022. (e) Hernández, F.; Lumetzberger, A.; Avendaño, C.; Söllhuber, M. Synlett 2001, 1387. (f) Liu, J. F.; Ye, P.; Zhang, B.; Bi, G.; Sargent, K.; Yu, L.; Yohannes, D.; Baldino, C. M. J. Org. Chem. 2005, 70, 6339.

17. (a) Snider, B. B.; Zeng, H. Org. Lett. 2002, 4, 1087. (b) Snider, B. B.; Zeng, H. J. Org. Chem. 2003, 68, 546.

18. (a) For nM inhibitors see: Rosen, T. J.; Coffman, K. J.; McLean, S.; Crawford, R. T.; Bryce, D. K.; Gohda, Y.; Tsuchiya, M.; Nagahisa, A.; Nakane, M.; Lowe, J A. III Bioorg. Med. Chem. Lett. 1998, 281. (b) For a brief description of SP binding inhibition studies using ${ }^{125}$ I-BoltonHunter labeled SP see Wong, S.-M.; Musza, L. L.; Kydd, G. C.; Kullnig, R.; Gillum, A. M.; Cooper, R. J. Antibiotics 1993, 46, 545.

19. (a) Tomoda, H.; Omura, S. Pharm. Therapeutics 2007, 115, 375. (b) For the preparation of tritiated-EBOB see Palmer, C. J.; Casida, J. E. J. Labelled Compounds Radiopharm. 1991, 29, 829.

20. Personal communication from Professor Yoshihisa Ozoe. All $\mathrm{IC}_{50}$ values are averages of three trials. 
21. (a) Watanabe, T.; Arisawa, M.; Narusuye, K.; Alam, M. S.; Yamamoto, K.; Mitomi, M.; Ozoe, Y.; Nishida, A. Bioorg. Med. Chem. 2009, 17, 94. (b) Yamamoto, K.; Nishida, A.; Arisawa, M.; Ozoe, Y. Japanese Patent 184420, 2008.

22. Hart, D. J.; Magomedov, N. Tetrahedron Lett. 1999, 40, 5429.

23. Hart, D. J.; Magomedov, N. J. Am. Chem. Soc. 2001, 123, 5892.

24. (a) Pellegrini, C.; Strässler, C.; Weber, M.; Borschberg, H.-J. Tetrahedron: Asymmetry 1994, 5, 1979. (b) For a recent paper describing indole-to-oxindole transformations see Lopez-Alvarado, P.; Steinhoff, J.; Miranda, S.; Avendaño, C.; Menéndez, J. C. Tetrahedron 2009, 65, 1660.

25. Ottenheijm, H. C. J.; Plate, R.; Noordik, J. H.; Herscheid, J. D. M. J. Org. Chem. 1982, 47, 2147. 26. Plate, R.; Nivard, R. J. F.; Ottenheijm, H. C. J. J. Chem. Soc., Perkin Trans. 1 1987, 2473.

27. Itoh, A.; Ozawa, S.; Oshima, K.; Nozaki, H. Tetrahedron Lett. 1980, 21, 361.

28. Mazurkiewicz, R. Monatsh. Chem. 1989, 120, 973.

29. Kende, A. S.; Fan, J.; Chen, Z. Org. Lett. 2003, 5, 3205.

30. Chen, Z.; Fan, J.; Kende, A. S. J. Org. Chem. 2004, 69, 79.

31. Heredia, M. L.; de la Cuesta, E.; Avendaño, C. Tetrahedron 2002, 58, 6163.

32. Staudinger, H.; Meyer, J. Helv. Chim. Acta 1919, 2, 635.

33. (a) Takeuchi, H.; Eguchi, S. Tetrahedron Lett. 1989, 30, 3313. (b) Takeuchi, H.; Hagiwara, S.; Eguchi, S. Tetrahedron 1989, 45, 6375.

34. For a review of $N$-acyliminium ion of relevance see Avendaño, C.; de la Cuesta, E. Curr. Org. Synth. 2009, 6, 143.

35. Hart, D. J.; Oba, G. Tetrahedron Lett. 2007, 48, 7069.

36. Unpublished results from the authors group with Dr. Gabriel Oba.

37. Leca, D.; Gaggini, F.; Cassayre, J.; Loiseleur, O.; Pieniazek, S. N.; Luft, J. A. R.; Houk, K. N. J. Org. Chem. 2007, 72, 4284.

38. Walker, S. J.; Hart, D. J. Tetrahedron Lett. 2007, 48, 6218.

39. (a) Martín-Santamaría, S.; Espada, M.; Avendaño, C. Tetrahedron 1999, 55, 1755. (b) Sánchez, J. D.; Ramos, M. T.; Avendaño, C. J. Org. Chem. 2001, 66, 5731. (c) For an overview of the chemistry of pyrazino[2,1-b]quinzaline-3,6-diones see Avendaño, C.; Menéndez, J. C. Curr. Org. Chem. 2003, 7, 149.

40. Hart, D. J.; Magomedov, N. J. Org. Chem. 1999, 64, 2990.

41. Freed, J. D.; Hart, D. J.; Magomedov, N. A. J. Org. Chem. 2001, 66, 839.

42. Morin, R. B.; Jackson, B. G.; Mueller, R. A.; Lavagnino, E. R.; Scanlon, W. B.; Andrews, S. L. J. Am. Chem. Soc. 1969, 91, 1401.

43. Ortiz-Barbosa, Y. A.; Hart, D. J.; Magomedov, N. A. Tetrahedron 2006, 62, 8748.

44. Magomedov, N. A. Ph.D. Thesis, The Ohio State University, 2000.

45. Unpublished results from the author's group with Dr. Angela J. Winstead and Ms. Grace Mbogo.

This reaction was modeled after the following report: Surygina, O.; Ehwald, M.; Liebscher, J. Tetrahedron Lett. 2000, 41, 5479.

46. Chen, S. Ph. D. Thesis, Colorado State University, 2007. 
47. Williams, R. M.; Glinka, T.; Kwast, E.; Coffman, H.; Stille, J. K. J. Am. Chem. Soc. 1990, 112, 808.

48. Chen, S.; Williams, R. M. Tetrahedron 2006, 62, 11572.

49. Dr. Magomedov, his wife (Natalya) and son (Amir) died in a tragic accident on February 6, 2006.

\section{Author's Biography}

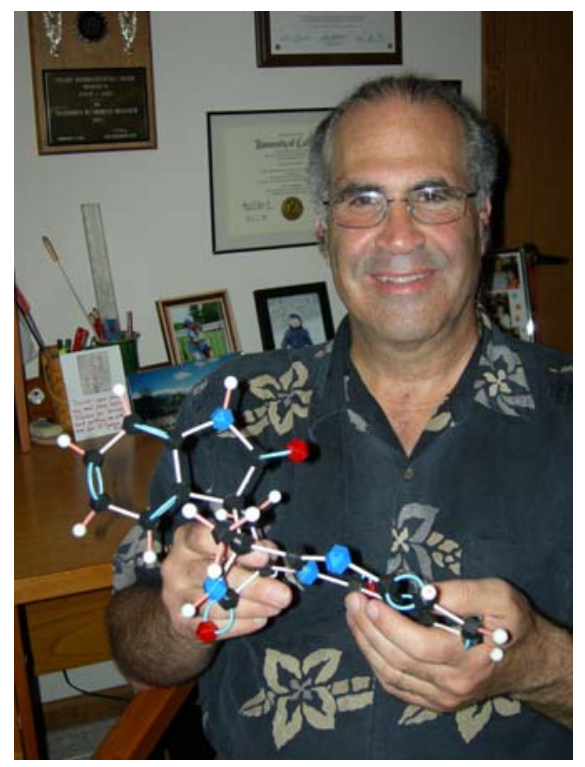

David J. Hart was born in Lansing, Michigan, USA in 1948. He received his BS degree from the University of Michigan in 1972 after serving as a conscientious objector for two years (19671969) during the Vietnam War. He then pursued graduate studies at UC Berkeley (PhD in 1976 with William G. Dauben) and postdoctoral studies at Caltech with David A. Evans. He moved to The Ohio State University Department of Chemistry in 1978 as an assistant professor where he remained on the faculty for 31 years. He is now the Melvin S. Newman and Emeritus Professor of Chemistry at OSU, and is continuing research in the areas of alkaloid synthesis, terpenoid synthesis, free radical chemistry and synthetic methods development with a small group of undergraduate students. 